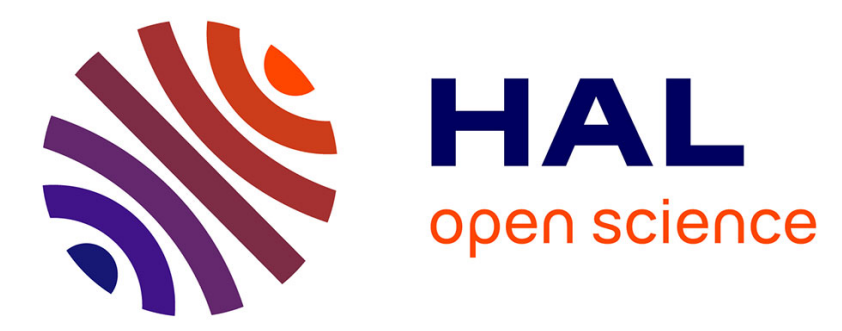

\title{
Une riche sépulture gallo-romaine découverte près de Niort (Deux-Sèvres) \\ Pierre-Henri Mitard
}

\section{To cite this version:}

Pierre-Henri Mitard. Une riche sépulture gallo-romaine découverte près de Niort (Deux-Sèvres). Gallia - Fouilles et monuments archéologiques en France métropolitaine, 1977, 35 (1), pp.201-237. 10.3406/galia.1977.1561 . hal-01939342

\section{HAL Id: hal-01939342 \\ https://hal.science/hal-01939342}

Submitted on 14 Jun 2020

HAL is a multi-disciplinary open access archive for the deposit and dissemination of scientific research documents, whether they are published or not. The documents may come from teaching and research institutions in France or abroad, or from public or private research centers.
L'archive ouverte pluridisciplinaire HAL, est destinée au dépôt et à la diffusion de documents scientifiques de niveau recherche, publiés ou non, émanant des établissements d'enseignement et de recherche français ou étrangers, des laboratoires publics ou privés.

\section{(ㅇ)(1) $\$$}

Distributed under a Creative Commons Attribution - NonCommercial - NoDerivatives| 4.0 


\title{
UNE RICHE SÉPULTURE GALLO-ROMAINE DÉCOUVERTE PRÈS DE NIORT (Deux-Sèvres)
}

\author{
par Pierre-Henri MITARD
}

Il s'agit de la découverte d'un sarrophage, faitre an mois d'aoùt 1973), à l'orcasion de travaux de terrassement pour la construction d'un magasin à la sortie sud-ouest de .iort. ${ }^{1}$; apres mise au jour de la partie supérieure et ouverture par les obveriers, le sarcophage fut détoure à la pelle mécanique, avec réserve d'une gaine de terre pour éviter la détérioration de la pierre. Cette opération fit apparaitre le long du còté est des éléments mobiliers, tranchés par la pelleteuse. Ceux-ci furent remarqués par des visiteurs qui pratiquèrent des sapes dans la gaine de terre et récupérèrent ainsi un important matériel. C'est seutement après rette intervention qu'il nous fut donné de nous occuper du sauvetage ${ }^{2}$ de rette sépulture, et que nous avons eu la chance de nous voir remettre l'ensemble des trouvailles faites clandestinement par un jeune fouilleur; mais un autre fouilleur clandestin au moins a ignoré notre appel, ou y est resté sourd. L'essentiel parait rependant avoir éte saluré.

\section{Desscription (pl. 1).}

Tecouverte en fait sur le territoire de la commune de Bessines (au lieu-dit Les Ciuéringousses, parcelle $\mathrm{n}^{0} 50$, section $B$ du cadastre), la sépulture se situait à $3 \mathrm{~km}$ du centre de la boucle de la Sèvre Niortaise, on se localisent les quartiers antiques de Niort. L'emplacement correspond à une zone relativement basse et humide, à $80 \mathrm{~m}$ à l'est du bord de la route nationale 11, mais aussi à 100 m à l'ouest d'un chemin paraissant fort ancien (conduisant à Saint-Symphorien).

La commune de liessines n'a guère fait parler d'elle sur le plan archéologique?.

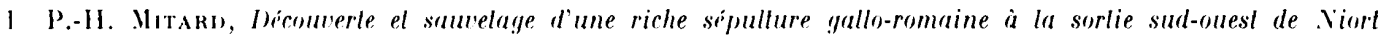

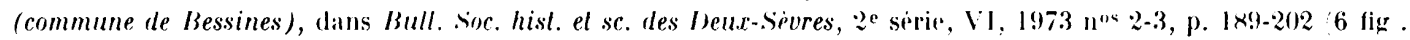

2 Avec lautorisation du proprichaire du terain, M. Ciambiasi, qui a fait abandon de la propriete des petits objets decouverts en faveur du Musée de Niort, el de .1. G. Nicolini, directeur des Antiquités historiques de la région Poitou-charentes. Les objets ont ite effectivement remis at Musere d'Antiquites de Niort an mois danout 1976.

3 E. Roy et L. Desalvaf, La colonne de Pierre Levée (press de Bessines), dans Bull. sinc. stalistique des Deur-Siveres, V, 1 $\times \times:-1 \times \times 4$, p. 10-13. 


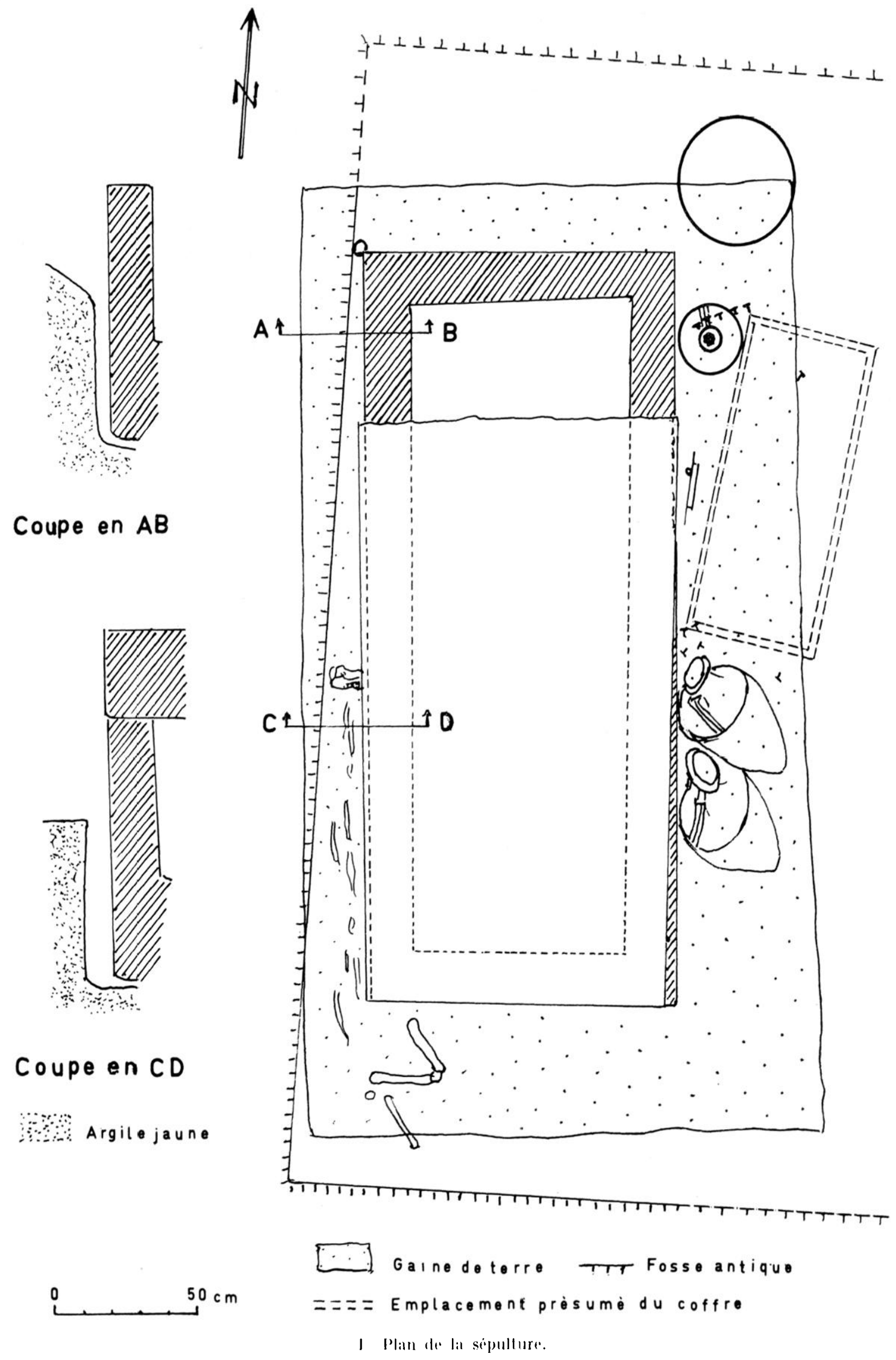




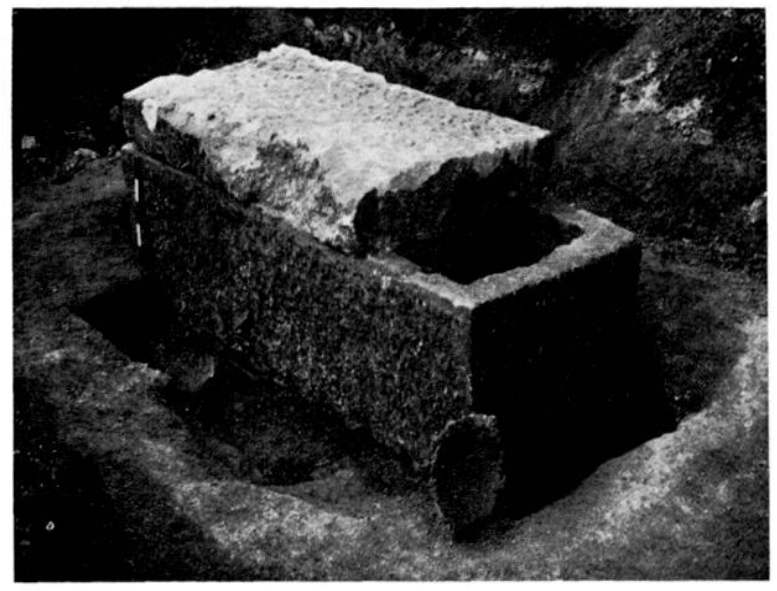

1 Le sarteophitge ril du nomblest: au premier plan, ampreinte de lat erande cruche.

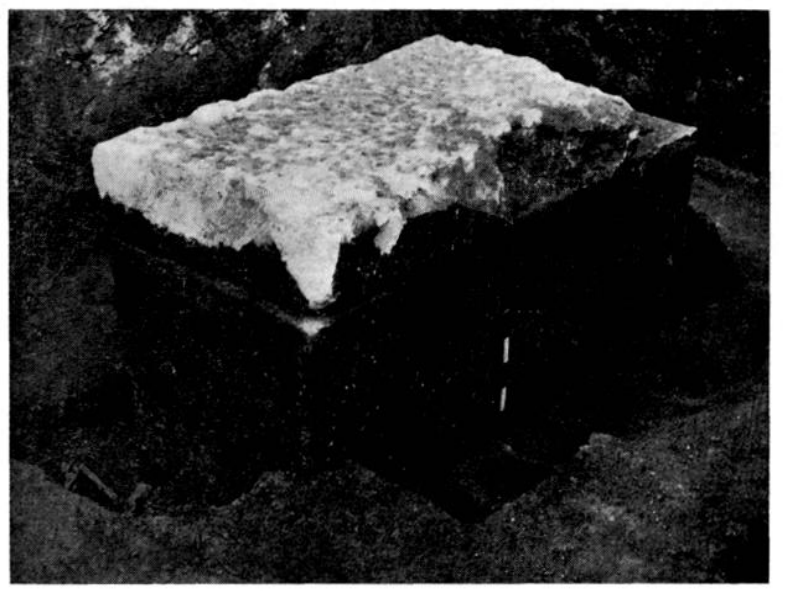

$\therefore$ Le sitreophinge; vu du sud-erst.

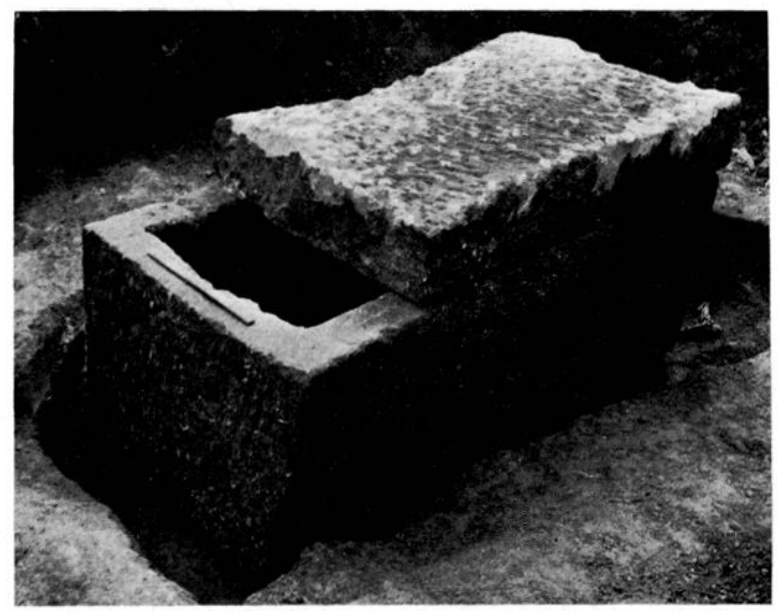

3 l.c sarcophage, vil du nord-ouest.

Cependant lors du sauvelagere lant atux abords immédiats du sareophage (déblais, gaine de (erre) qu'aux alentours sur la surface déape par le bulldozer (environ $2000 \mathrm{~m}^{2}$ ), nous avons recueilli plus de $3 \mathrm{~kg}$ de lessons de ceramique datable du ve siède avant notre ère ${ }^{4}$ et altestant par conséquent une orerupation des lieux beaucoup phus ancienne.

En revanche, en dehors des abords immédiats de la sépulture, les tessons d'époque, romaine étaient extrèmement rares at nous n'avons rien remarqué en particulier qui puisse révéler la présence d'une autre sépulture.

Le sarcophage. Lux dires de personnes ayant assisté aux lravaux ayant amené la découverte, le sarcophage n’aurait été protégé que par une rouche de terre d'une vinglaine de centimetres.

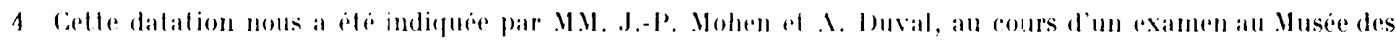
Antiquites nationales. les lessons redivent de plusieurs lypes : les uns epais jusqu a l coll a pale noire, degraissant

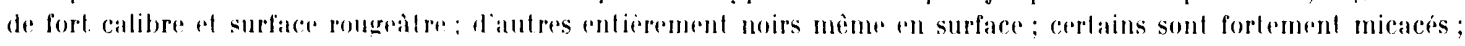
d'autres, moins nombreux, sont plus fins : plusieurs portent de's decors d'impressions an doigl sur le bord ou all-dessous, l'un d'eux un cordon en relief avere protubiraner. Cies tessons rappellent par leurs profils ou leurs decors des exem-

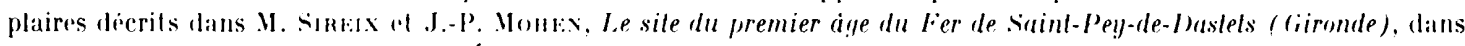
Bull. Soc. préh. Francaise, bx, 1971, Btudes on travalux, p. 451-t5x. 
Orienté nord-sud, tête au nord, avec un décalage de 5o ouest à la tête (par rapport au nord marnétique), il frappail par ses dimensions importantes. Cave : long. : 2,35/2,38 m ; larơ. : $1.08 \mathrm{~m}$ à la tête. $1.02 \mathrm{~m}$ au pied. au bord de la cuve ; plus faible a la base : 0,97 et $0.93 \mathrm{~m}$; haut. : $0.80 \mathrm{~m}$ (en moyenne); dimensions intérieures au fond : $1.95 \times 0,65 \mathrm{~m}$; prof. : $0,45 / 0,48 \mathrm{~m}$; épais. des parois : de 15 a $17 \mathrm{~cm}$; du fond : env. 35 cm. Counercle : long. : 2,56/2,44 m ; larg. : 1,10 m (en moyenne) ; épais. : $0,28 \mathrm{~m}$. C'est à l'extrémité tìte que le couvercle débordail la cuve; il a été découvert fendu transversalement.

Les dimensions de la cuve sont à peu de chose près les mèmes que celles des plus grands sarrophages ornés d'Arles ${ }^{5}$. Mais la pierre est ici simplement taillée avec soin, comme pour un usage architectural : la cuve présente des parements bossagés, avec ciselures aux angles et au bord ${ }^{6}(\mathrm{fig} .1$ a 3$)$.

La partie horizontale du bord de la cuve avait été soigneusement égalisée, comme la partie du couvercle s'appuyant dessus. Malgré ce souci de bon ajustage, en raison d'une planéité générale insuffisante de l'un ou de l'autre, il subsistait aux pieds un jour entre les deux éléments atteignant jusqu'à $4 \mathrm{~cm}$, ce qui a permis une légère infiltration de terre.

Suivant une suggestion qui nous avait été faite sur place par un ouvrier maçon travaillant au chanticr voisin, la pierre, un calcaire, parait bien provenir de la carrière de souché (ancienne commune maintenant rattachée à Niort, à l'est de la ville), à un peu plus de $う \mathrm{~km}$ de là, à vol d'oiseau. La probabilité en a été confirmée par la comparaison d'échantillons prélevés sur le sarcophage et à la carrière (sur une paroi proche de l'entrée)? Il n'est cependant pas possible d'aboutir à une certitude dans ce domaine, étant donné l'élendue éventuelle du niveau géologique correspondant.

Au moment de l'extraction et du transport par une grue au point où le sarcophage est désormais conservé ${ }^{8}$, nous avons pu en faire prendre le poids a l'aide d'un peson : couvercle compris, il atteint 4 tonnes. Quant a la mise en place, les observations faites au cours de la fouille nous ont permis de comprendre comment elle avait eu lieu. La fosse antique comblée de terres mélangées se distinguail netlement de la couche naturelle inférieure d'argile jaune. Elle dépassait largement la longueur du sarcophage à la tête et aux pieds, mais landis que le profil de sa paroi ouest apparaissait clairement dans la coupe de la graine de terre laissée par la pelleteuse de ce còté -.. où le sarcophage n'en était distant que de 5 a $20 \mathrm{~cm}$. còté est son profil nord-sud se découpait dans la paroi de la fosse artificielle creuscé par la pelleteuse. mais le fond en était à $60 \mathrm{~cm}$ plus haut qu'a l'emplacement du sarcophage, distant de $1,60 \mathrm{~m}$. Il apparaissait donc que du còté est. la fosse antique présentait un plan incliné à environ 35) ou $40 \%$. sur lequel le sarcophage avait grlissé jusqu'au fond.

Le contenu. Le sarcophage contenait un squelette, non recouvert de terre, et un peu de mobilier.

L'étude anthropologique (Annexe 1) montre que le squelette était celui d'une jeune femme d'une vingtaine d'années environ9. Ceette étude fait d'autre part état de fragments

5 E. Espitananter, Recueil geniral des Bas-reliefs... de la Giaule romaine, nos 133, 166 en particulier, celui-c datable du debut du $u^{\mathrm{e}}$ siecle, selon J.-J. Hatr, La lombe gallo-romaine, 1951, p. 113.

6 Cf., pour ces détails techniques, P. Vanixe, sur la taille de la pierre anlique, míliévale el moderne, centre de Recherches sur les techniques gréco-romaines, fasc. n" 3, 197.1, pl. 17.

7 Comparaison effectuée sur coupes minces par .I. Robert Mathieu all Laboratoire de micropaleontologie de l'Cniversilé de Paris VI : selon ce spécialiste, en rffet, il s'agit d'un calcaire bioclastiqur comportant des débris de lamellibranches tres nombreux, d'échinodernes et de bryozoaires fu'on retrouve sous des aspects voisins dans les deux échantillons. Qu'il nous soit permis de remercier ici M. Mathieu, ainsi que M. Blanc, du Laboratoire de géologie, qui nous avait procuré les coupes minces.

8 Devant l'entrée du magasin dont la construction a amené la découverte : dans le transport l'orientation s'est trouvée inversée.

9 Cette êtude n'a sur ce point fait que confirmer un examen préliminaire effectué, au Laboratoire danthropologie phỵsique, par . Mthe Ferembach et -.. pour les dents - par .I. J. Wénard. 


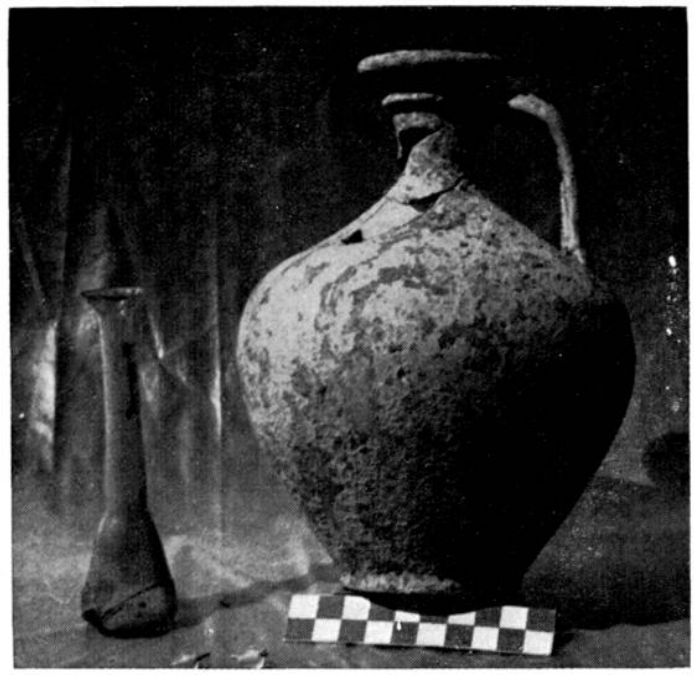

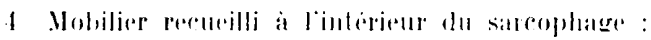
crurbere halsamaire ol perles.

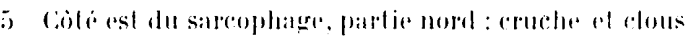

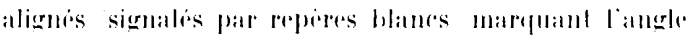
du coffre an bois.

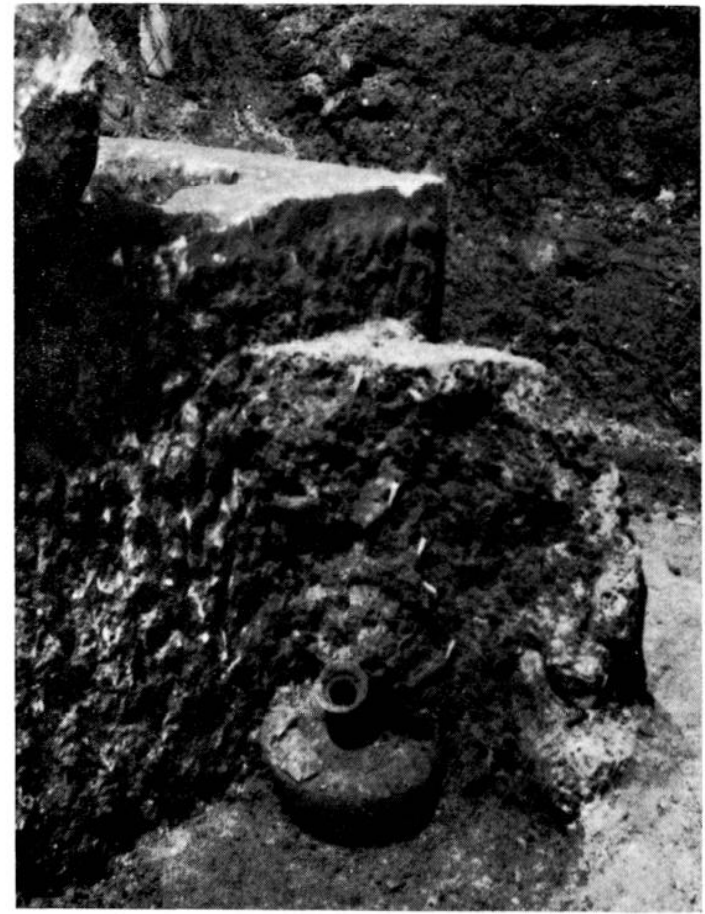

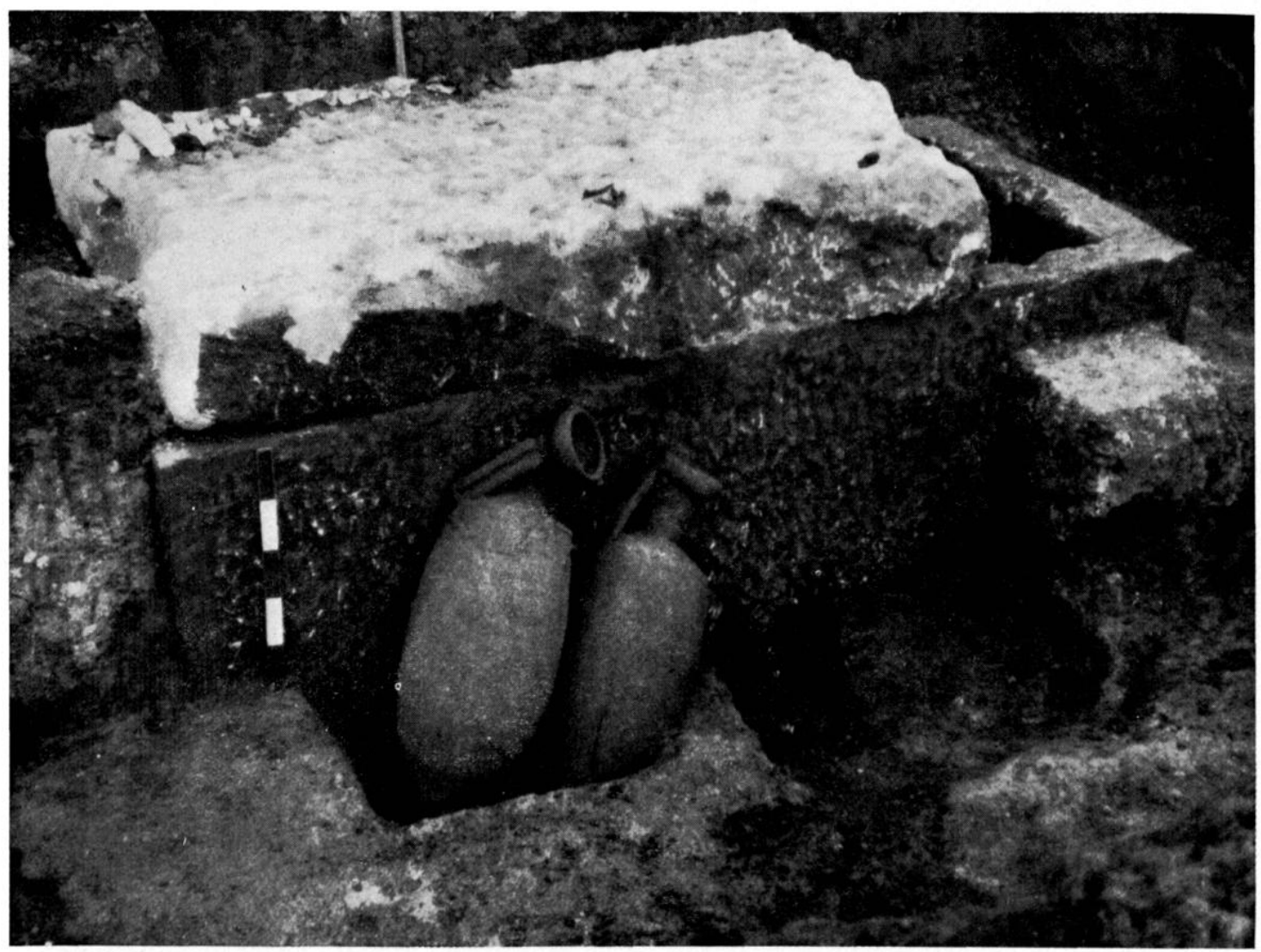

6. I.es amphores en place. 
d'un crâne de très jeune enfant, peut-être mème de foxtus ; on ignore malheureusement l'emplacement du dépôt correspondant : recueillis par nous dans une petite motte de terre rejetée sur les déblais, nous ne pouvons dire s'ils provenaient de l'intérieur ou de l'extérieur du sarcophage, et aucun autre élément du même squelette n'a été remarqué.

Le crâne féminin se trouvait, quant à lui, aux dires des ouvriers, à $300040 \mathrm{~cm}$ de la paroi nord de la cuve; au-dessus et à droite, avaient été déposés une cruche en céramique, trouvé renversée vers la gauche, et, entre la cruche et le crâne, un petit balsamaire en verre; quelques perles en verre ont d'autre part été trouvées au niveau du cou (lig. 4). Il faut ajouter à ce mobilier leux monnaies recueillies par notre équipe dans la moitié inférieure du sarcophage. ainsi que le corps d'un poulet, attesté par les fragments osseux recueillis dans les mêmes conditions (roir Annexe 2). Ces fragments ne comprenant ni la tète, ni les pattes, il nous paraît possible d'imaginer que la bête avait été comme préparée pour la consommation (l'absence de quelques autres éléments moins caractéristiques s'expliquant, eux, par les conditions du sauvetage).

Les dépôts. Coest autour du sarcophage qu’avaient été accumulés les dépôts qui marquent la richesse de cette sépulture, dépôts mobiliers (céramique, verrerie) d'une part, dépôts alimentaires (représentés par des ossements d'animaux) d'autre part.

a) Dépôts mobiliers:

a l'angle nord-ouest, un petit gobelet a paroi sablée, tris incomplet, bien que nous l'ayoas dégagé nous-mèmes a $50 \mathrm{~cm}$ sous le bord de la cuve ;

à l'angle nord-est. une grande cruche. malheureusement mise en pieres par la pelleteuse (fig. 1): un peu plus au sud, une petite cruche (fir. 5) ;

dans la moitié sud, deux amphores appuyées contre le sarcophage (fig. (i) et auxquelles il manquait à chacune une anse: l'une des anses manquantes. celle de la première á partir du sud. retrouvée légérement engagée sous le sarcophage derriere la seconde amphore, avait dù céder lors du dépòt ; la panse était éclatée còté sarcophage, peut-être à la suite du heurt qui en était résulté :

entre les amphores et les cruches, un coffre en bois rempli d'une cinquantaine de pièces de vaisselle en verre et en céramique, dont l'existence fut révélée par le passage de la pelleteuse, el les éléments épargnés par celle-ci extraits par les fouilleurs clandestins.

On remarquera que les membres de la fámille, ou amis de la défunte, avaient pu, pour déposer leurs offrandes, utiliser le plan incliné ménagé pour la descente du sarcophage.

Le coffre et sa serrure. La présence du coffre est attestée par les pièces en fer qui lui appartenaient et que nous avons pu heureusement retrouver en place :

une serrure, plaquée contre le sarcophage, id 6j/85) an de l'angle nord-est (fig. 7);

une rangée de 6 clous (de 3 a $5 \mathrm{~cm}$ de long) alignés presque verticalement sur $4: 3 \mathrm{~cm}$ (fig. 5 ) ce qui en donne la hauteur approximative ainsi que quelques autres dispersés notamment à 1 mètre plus au sud - ce qui en donne la longueur approximative;

quelques fragments de brides de fer avec restes de bois y adhérant, les uns plats, d'autres formant un angle droit fixés par des clous à tête large $($ diam. : $1 \mathrm{~cm})$ très rapprochés, permettant d'imaginer un renforcement du coffre, en particulier aux angles ou au bord du couvercle.

On avait donc là un coffre d'environ $1 \mathrm{~m}$ de long (peut-être un peu moins), $45 \mathrm{~cm}$ de haut, et peut-être étant donné l'abondance relativement limitée des fragments recueillis 
dans les déblais constitués par la pelleteuse, qui implique un débord du coffre par rapport à la gaine de terre lui-même limité $-45 \mathrm{~cm}$ de large. Le contenu avait d'ailleurs dù, étant donné la pente du fond de la fosse, se renverser en direction du sarcophage, ce qui a permis à un plus grand nombre de pièces d'échapper à la destruction lors du détourage à la pelleteuse.

La serrure comporte un loquet ou pène à ressort, d'un type bien connu à l'époque gallo-romaine ${ }^{10}$, mais les exemples de serrures completes sont rares et nous n'en arons pas trouvé de mème type pour étayer l'interprétation ${ }^{11}$. Nous en donnons un relevé fondé sur la position des divers éléments lors de la découverte (fig. 8) et sur la radio qui en a été faite par la suite ${ }^{12}$. Elle comprend (pl. II) :

une plaque de protection de $19,5 \times 12 \mathrm{~cm}$ environ. fixée (par huit clous à tète large) sur la paroi verticale du coffre, percée d'une entrée en équerre pour le passage de la clef, et échancrée sur un còté pour le passage de la tite du loquet:

un loquet (l) comportant trois lames-ressorts (r) à une extrémité el, à l'autre - qui restait dégagée gràce à l'échancrure de la plaque , un bouton (b) de préhension et une tìte plate (t), dans un plan perpendiculaire à celui du corps de la pièce et pouvant glisser sur les bords de l'échancrure. lors des mouvements de va-et-rient;

une plaquette ( $p$ ) allongée, portant une barrette (ba) transversale, devant servir au blocage des lames-ressorts, et un ergot (e) transversal également, qui concourait peut-ôtre à la fixation de la plaquette ; celle-ci devait ètre encastrée dans la partie supérieure de la paroi du coffre; nous avons trouvé cette plaquelte en position de chant (voir. fig. 8). mais cette position ne pouvant être fonctionnelle, nous avons basculé la pièce à $90^{\circ}$ pour le relevé (pl. II, 2);

une pièce en équerre (eq) dont l'extrémité supérieure en biseau avait dû faciliter sa fixation dans le couvercle ; c'est le seul élément que nous possédions pour imaginer comment celui-ci pouvait se trouver bloqué par la serrure; il jouait le ròle de moraillon et suppose qu'à son niveau la paroi de bois du coffre comportait une saignée pour permettre son passage;

une grosse pointe (po) trouvée accolée à la plaque, près d'un angle inférieur, n'est pas expliquée.

Pour que la serrure puisse fonctionner, il fallait que la plaquette (p) ait été fixée au-dessous de l'entrée, donc plus bas que ne le suggérait la position au moment de la découverte. C'est ainsi que nous l'avons figuré dans la coupe théorique transversale de l'ensemble du dispositif, tel que celui-ci nous paraît pouvoir être restitué (pl. II, 4). Le fonctionnement devait être le suivant : la clef introduite de la main droite (par l'entrée en équerre), prenant appui sur la plaquette (p), soulevait les lames-ressorts qui pouvaient ainsi passer au-dessus de la barrette (ba); le loquet ainsi débloqué, manoruvré de la main gauche, libérait la pièce eq et par lá mème le converele.

10) (f. B. Hofmax, La guineaillerie anlique, 3e parlie, Groupe areh. antique Touring-club de France abrégé:

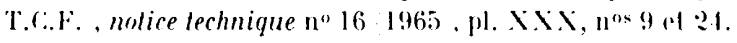

11 Voir denx itudes interessant des élements decouverts an Gaule : c. Cocktous, La serrure laconienne a

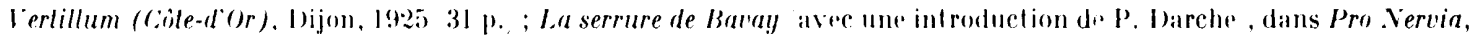
II, 19:26, p. 1633-173. L,a serrure de Balvily, qui devait fermere un coffe funeraire, présente bien un péne à ressort. comme ici, mais celui-ci, fixi an couverele, descendail verticalement dans une gaine, incluse dans la partip encastré dans lat paroi du coffere el oi il se blequait.

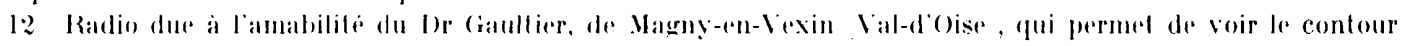

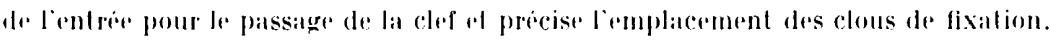




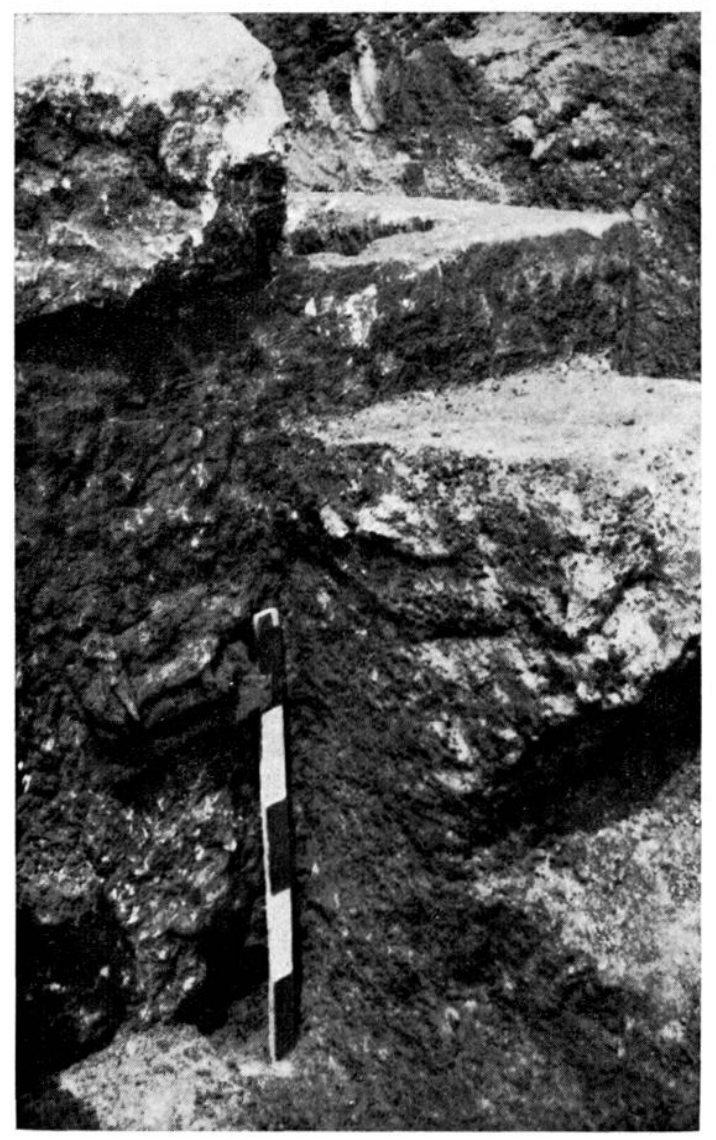

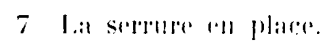

9 Ossements depore membreposterienr enconmexion analomigue, a langle subl-ourest du sareophage.

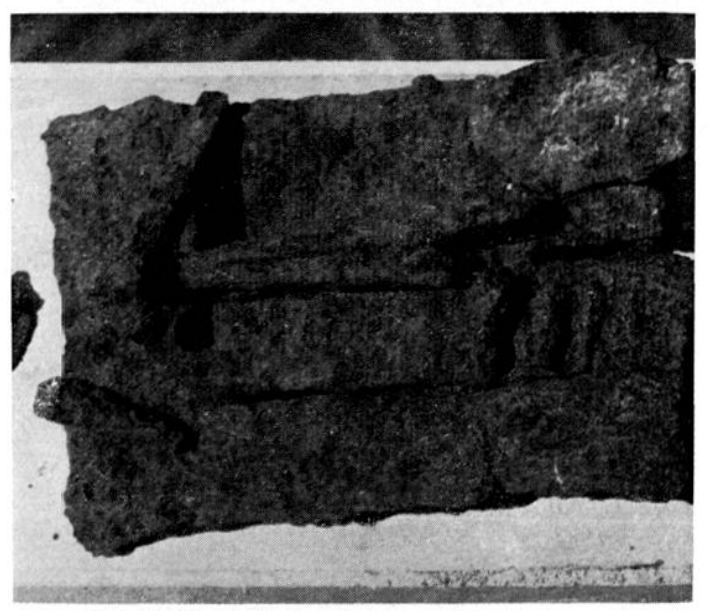

$x$ lat serrure apries nellogitge.

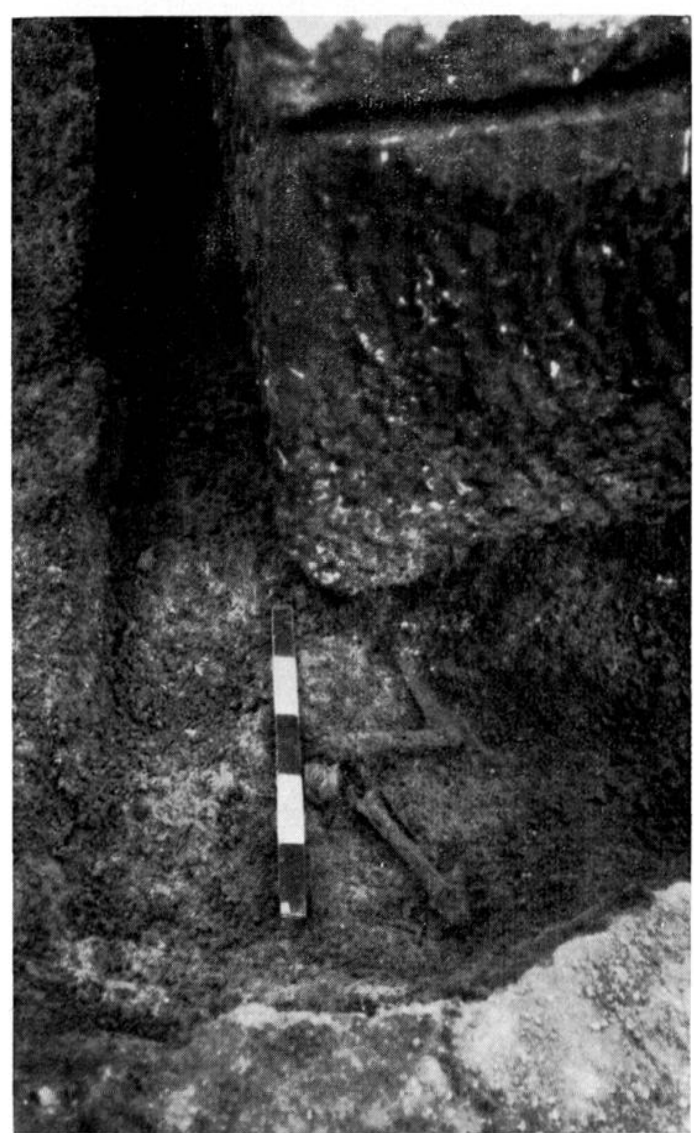

b) Dépoils alimentaires. Ies dépòts les plus carartéristiques sont reux qui rorrespondent aux ossements recueillis de long de la paroi ouest du sarcophage, depuis un point situé à $1,10 \mathrm{~m}$ de l'angle sud, et au-delà de celui-ci sur une cinquantaine de centimetres. L'espare disponible pour les recevoir entre le sarcophage et la paroi de la fosse allait d'une dizaine de centimitres à peine au nord, à une vingtaine à l'angle sudl. Au-dela de celui-ci, l'espace n'était pratiquement pas limité vers l'est, ce qui arait permis un etalement des ossements 

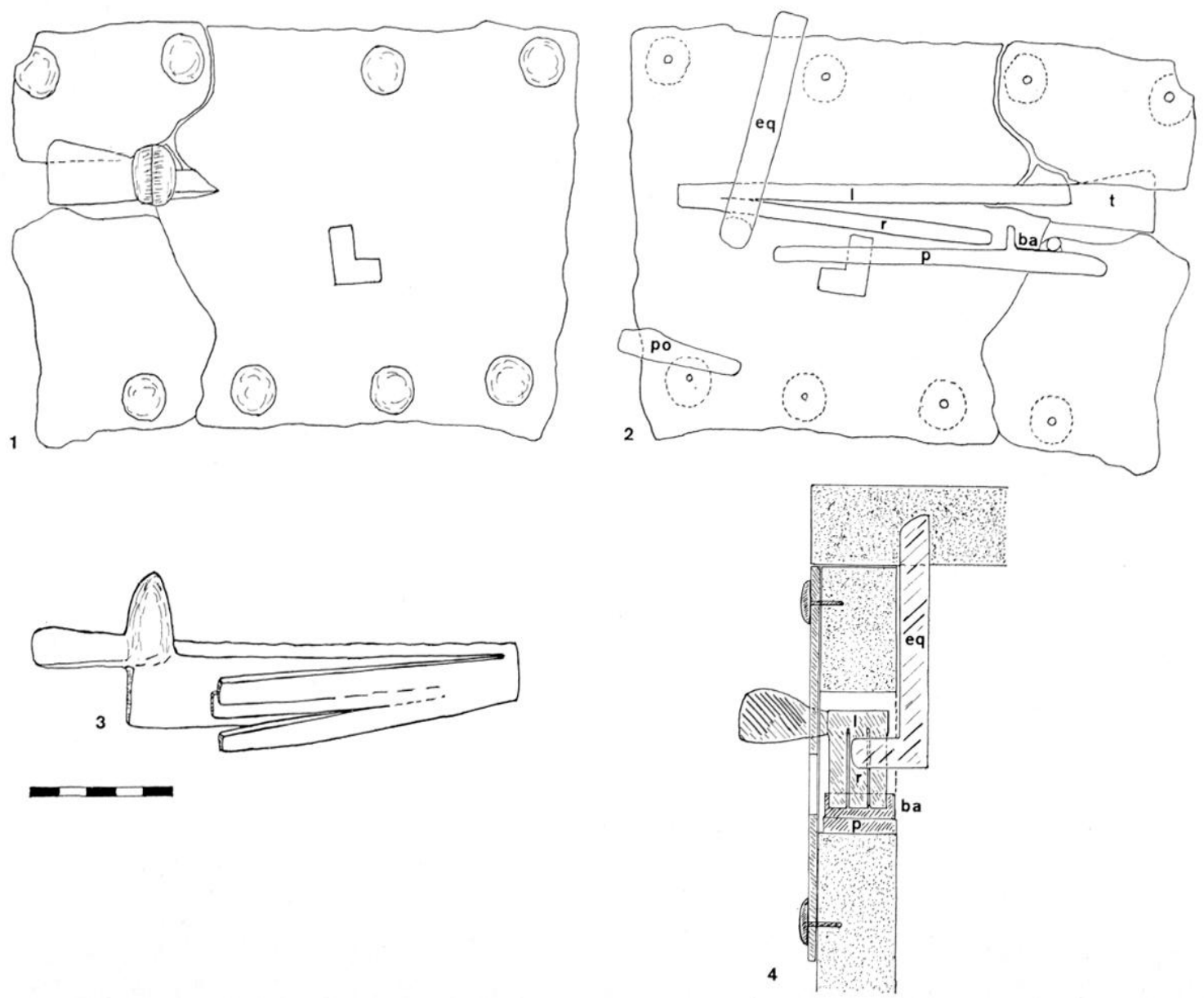

II La serrure : 1, face extérieure; 2, face intérieure; 3, lorfuet à ressort ; 4, restitution en coupe, lames ressorts en position de hlocage; les pieces figurés ne sont pas toutes sur le même plan.

que nous avons pu mettre en valeur (fig. 9) obtenant ainsi la preuve de leur maintien en connexion anatomique. Il y a tout lieu de penser qu'il en était de même pour ceux qui n'ont pu être extraits que dans des conditions moins favorables, plus au nord.

L'étude ostéologique (Annexe II, La fosse) montre que ces ossements provenaient des moitiés gauches de trois pores. Ces trois moitiés de pores devaient être pratiquement complètes au moment de leur dépòt. Les éléments de crânes portent la trace du sciage. Le demi-crâne le plus complet se trouvait a l'extrémité nord du dépòt, les membres antérieurs un peu plus au sud, les membres postérieurs prés de l'angle sud-ouest et au-delí, dans l'ordre anatomique normal par conséquent, comme si les trois moitiés de porc avaient été déposées sans débitage. A noter aussi l'absence de l'extrémité des membres, en particulier des sabots. Ce détail nous parait indiquer qu'il s'ayrissait de quartiers de viande préparés comme pour la consommation.

I'autres vestiges osseux ont, d'autre part, été recueillis dans les déblais, constitués principalement par la pelleteuse du còté est, et mème, pour quelques-uns, sous le sarcophage après extraction de celui-ci. L'inventaire en est donné dans l'étude jointe (Annexe II. Les déblais el Sous le sarcophage). Leur intérèt est moindre, étant donné qu'on ignore le lieu exact de leur dépòt. Quant à leur interprétation, on peut penser soit à des dépòts véritables, analogues à ceux du còté ouest, soit a des reliefs du repas funéraire. Celui-ci aurait alors eu lieu arant le rebouchage de la fosse, puis- 
que les déblais dans lesquels ont été recueillis ces ossements provenaient des niveaux de comblement; les quelques pièces trouvées sous le sarcophage avaient pu y ètre entrainées avec les terres de comblement que l'on y a efiectivement observées.

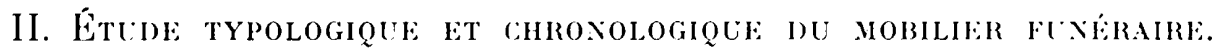

Dans l'étude qui suit, lorsque la provenance de l'objet n'est pas indiquée, il s'agit d'éléments provenant du coffre, ou présumés tels fragments recurillis dans les déblais constitués par la pelleteuse, côté est).

A. Monnaies.

Deux as de Claude Ier (41-54) (cuivre, d. $26 \mathrm{mmm}$; poids 5.80 g et $8.72 \mathrm{~g}$ ). Prov. sarcophage.

1. [TI GLAVD] IVS GAESA'R AVG P.V TRP IMP, ou IMP PP.

'Tête nue à g.

Rev. I.IBERTAS AVGVSTA: Ia liberté debout à dr. tenant un bonnel el lendant la main g. S.C.

Cohen 47 - HMC 145 (pl. 35.3) ou 2014 (pl. 36.6) . RIC. 69.

2. 'TI CIAVIIVS GAKAAR AVG PM TR P IMP, ou IMP PP.

Tête nue à g. paraissant bien relle de Claude.

Rev. Minerve debout à dr. langant un javelot et lenant un hourlier. sia.

Cohen 84 - BMC 149 (pl. 3i).4) ou 207 (pl. :36.7) - RIC. (66.

Rome (ou imitalion), année 41 ou 42 et s.

Ces deux pièces sont tris oxydées et de lecture difficile.

B. C'éramique.

Les numéros d'ordre renvoient a la pl. III, sauf ceux affectes d'un asterisque fpieces non reproduites).

a. C'éramique sigilléé.

1. Plat en terre beige brun clair el vernis rougre brun. H. $3.7 ;$ d. 15.3 (m.m. Estampille S.MBI.XI (barre du X a l'envers).

Forme Drag. 15/17, cf. Oswald-Pryce, pl. XIII-XIIII (aurun exemplaire strictement semblable; ce profil simplific est de l'avis de A. Vernhet plus proche des productions de Ilontans que de celles de Ia (iraufesenque). I'apris la matiere, ce plat parait issu de l'atelier de Monlans où la marque d'un S.MBINVS a d'ailleurs été retrouvée (C.I.L. XIII. 10.010. 1682. i II. I)urand-

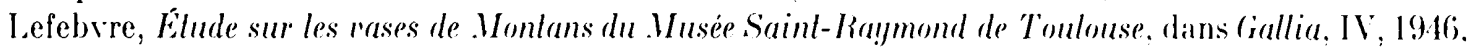
p. 169. nos 142, 144), alors qu'Oswald (Pollers' Stamps) altribue re polier enlierement a I a Graufesenque. J)atation : ()swald. Polters' Stamps : période flavienne (ou en arrondissant, 7()-95)) : Hofmann, Notice Technique Touring-(ilub de France no 22 : Yontans, j)-90.

2. Plat, terre un peu plus foncée que le précédent. II. 3,$7 ;$ d. I5,2 ('m. Listampille, de lecture difficile, incertaine. 1. Vernhet propose. sous toutes reserves, d'y lire MITV(GEXI), avec ligature MA, barre horizontale du $T$ a peine visible sur la droile el $V$ asse\% fermé. Matusenus est allesté à Montans et à La Graufesenque : a Montans sur formes ornées; a La Graufesenque, sur formes ornées (1)r. 29) et lisses; toutefois $\mathrm{A}$. Vernhet précise, en re qui concerne la (iraufesenque, qu'aucune des estampilles qui y ont été trouvées ne correspond à celle-ri. Malalion selon ()swald, Pollers' Stamps: Claude-Vespasien (soit, 4(1)-8(0).

Forme I)rag. 16; Oswald-Pryce, pl. XI.I, no 3 (époque de Claude). 
3. Tasse, terre beige, H. 5.3: d. 11.8 cm. Estampille ALBAN (proche d'une variété attestée à La (iraufesenque : renseignement A. Vernhet). Forme Drag. 27 (0)swald-Pryce, pl. XIIX); comme le $n^{0} 1$ ci-dessus, cette tasse paraît d'apres la matiere. issue de l'atelier de Montans, ou la marque d'ALBANVs a également été retrouvée (C.I.L. XIII, 10.010, 17, i - M. I)urand-Lefebvre. op. cit.. p. 145, $\mathrm{n}^{\circ} 4$, alors qu'()swald ('Polters' Stamps) attribue re potier entierement a La Graufesenque. Datation Oswald (Pollers' Stamps) : période Tibère-Vespasien (ou en arrondissant. 15̄-80).

*4. Tasse I)rag. 27. terre beige rose. vernis rouge brun très médiocre en partie disparu. H. 5.4; d. $11,7 \mathrm{~cm}$.

5. Tasse Jrag. 27, terre heige, vernis rouge brun. H. 3.9 ; d. $8.4 \mathrm{~cm}$.

6. Id. 11. 3,6; d. 8.1 cm. Intacte.

*7. Id. (d. $1: 3 \mathrm{~cm})$, représentée par une section de bord.

*8. Id. (d. $8(\mathrm{~cm})$, représentée par une section de bord el quelques fragments autres.

Les pièces 4 a 8 sont probablement issues de l'atelier de Montans. La forme I)ragr. 27 couvre le $\mathrm{I}^{\mathrm{er}}$ sichle et perdure jusque vers le milieu du $\mathrm{u}^{\mathrm{e}}$.

b. Céramiques à parois fines.

9. (iobelet ovoïde en terre beige ocré. micarée à engobe rouge brun (traces sur le bord). 11. $12.3 ;$ d. $10 \mathrm{~cm}$. Décor à la barbotine formant des épingles à cheveux en oblique et par groupe de trois, alternant avec des séries de lunules surmontées d'une petite flamme disposée verticalement. Tris incomplet.

Ce type de vase est fréquent dans la région, en particulier à siantes, avec diverses variétés de disposition des "épingles" et des "lunules", ainsi que de couleur de la pâte (souvent blanche), sous un engobe rouge brun. Voir le point fait par F. Mayet, La céramique à parois fines à décor non moulé du Musée de Saintes, dans Rec. Soc. arch. et hist. de la Charente-IIaritime, XXV, 1973-1974, p. 91100 .

Origine : Gaule centrale, probablement Lezoux.

Datation : 80-100 (éventuellement jusqu'à 120). Confirmée par deux contextes de trouvailles récentes : un dépotoir près des arènes de saintes, datable du dernier quart du ver siècle (A. Andrillon et M. Rouvreau, dans Rec. Soc. l'arch. el d'hist. de la Charente-Ylaritime. XXIV, 1972, p. 227-254); un puits comblé avec un important matériel céramique ${ }^{13}$ en une seule fois. probablement vers 70-80 à Saintes (M.-H. et J. Santrot et I). Tassault. dans (iallia, 33, 1975), p. 117-158). Le début des vases de ce type pourrait mème ìtre plus précoce ; cf. un exemplaire à Entrains (Niève), dans une fosse qui serail datable du rògne de Yéron au plus tard.

10. Petil gobelet ovoïde en terre beige brun clair, a paroi sablée (sable tris fin) et vernis noir métallescent, à l'intérieur comme à l'extérieur. $H .8,5 \mathrm{~cm}$ env. Trouvé à l'angle extérieur n.-o. du sarcophage (en place, déjà frag̣menté et incomplet).

Ce type de vase se rattache au précédent par la forme el la nature de la terre. Ies exemples se retrouvent dans les contextes précédemment cités à Saintes. Mais cet exemplaire en diffère par la rouleur de l'enłrobe. Sa datation est donc moins sùre. Cf. Gose. Ciefässtypen der Rämischen Keramili im Kheinland (1950), no 189, de Rheinzabern (plus grande taille et galbe un peu différent) de mème couleur d'engobe, daté de la première moitié du II $^{\mathrm{e}}$ siècle.

11. Petil gobelet, en terre crème à engobe terne mal conservé et de couleur inégale. allant du jaune orangé au brun verdâtre à l'extérieur. plus uniformément rouge orangé à l'intérieur. II. $8,5 \mathrm{~cm}$. Lne seule anse, d'ailleurs incomplète nous est parvenue; la seconde nous parait très probable bien que nous n'ayons pas trouvé d'exemplaires de comparaison de cette forme haute

13 Limportance de ce materiel fait netlement penser à un puits "funeraire" ou a offrandes, bien que les auteurs de l'etude n'aient pas cru devoir evoquer cetle idere. 


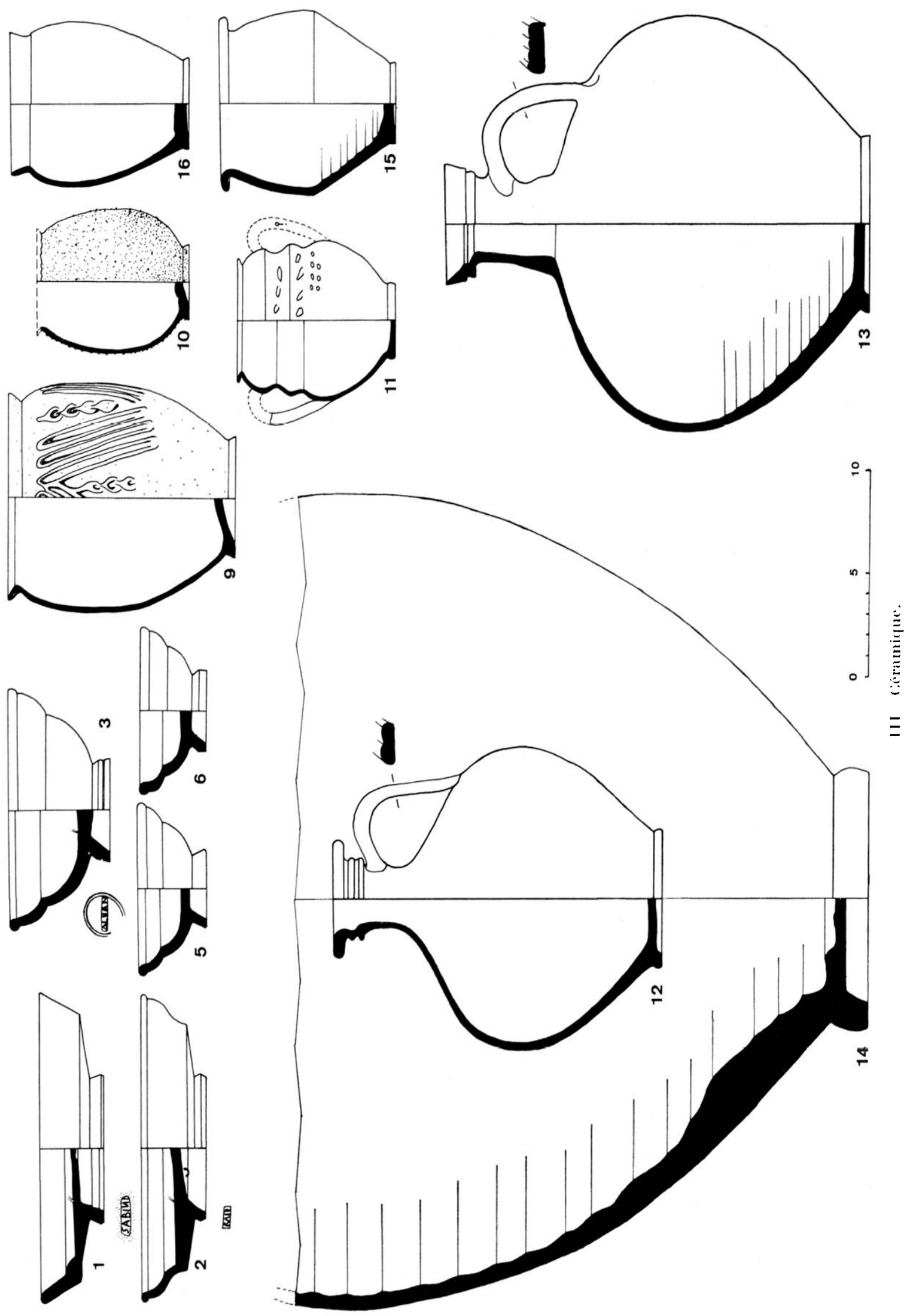


et à deux étranglements, étant donné la typologie des formes voisines ${ }^{14}$. Décor à la barbotine de petites perles les unes rondes, les autres allongées comme des grains d'orge. - Très incomplet.

Après avoir assisté (lors du congrìs 1976 de céramologie de la s.F.E.G.A.G. à Saintes. 2730 mai). à la présentation du matériel recueilli dans la fouille d'un atelier découvert en 1975 à PetitNiort. près de Mirambeau (Charente-Maritime), soit à une centaine de kilomètres au sud de Niort. il nous paraît très vraisemblable que ce petit gobelet provienne de cette dernière officine, qui produisait notamment des petits vases oroïdes à paroi fine. en terre blanche et engobe ocre rouge (cf. J. Gaillard et Cl. Rousselière. Four el dépotoir gallo-romains de Pelit-Wiort, Charente-Varilime, dans Bulletin d'information $n^{\circ}$ 14. novembre 197\%, de l'Association archéologique et historique Jonzacaise). Parmi les pièces recueillies dans un dépotoir figgure en particulier un vase à dépressions (op. cit., fig. $(\mathrm{I}-8)$ en exemplaire unique, mais qui ne doit pas venir de bien loin et dont la matière - moins bonne que celle des ovoïdes - est strictement identique (pâte et engobe) à celle du présent gobelet. Gageons que l'extension de la fouille de ce nouvel atelier apportera une confirmation de ce que nous avançons.

Datation de ces céramiques à décor à la barbotine entre 40 et 80, avec possibilité de prolongement jusqu'i la fin du I $^{\mathrm{er}}$ siecre. selon F. Mayet. Les céramiques à parois fines dans la péninsule. iberique. Pub. du Centre Pierre Paris (E.R.A. 522). 1975, p. 79.

\section{c. Céramique commune.}

12. Cruche à large col souligné de deux moulures, avec anse à deux nervures. H. 18 ; d. $15 \mathrm{~cm}$. Terre brun clair tendre, sans engobe. - Trouvée dans le sarcophage.

Jes cruches de formes trés voisines, à des variantes de détail près (intéressant tantòt le col, plus mince. tantot le galbe, plus écrasé). mais d'une matière différente, se retrouvent dans le puils de śaintes déjà cilé au no 9 ci-dessus (vases nos $112,113,114, \mathrm{pl} . \mathrm{X}$ ).

13. Cruche a col évasé, à profil dit "en amande" ou "en fer de lance", avec anse à quatre nervures. II. 23,5) ; d. $20 \mathrm{~cm}$. Matière identique à celle de la précédente, très tendre el fragile. Trouvée le long du côté est du sarcophage, extrémité nord ; écrasée et reconstituée.

Des cruches de forme semblable, mais de matière différente se retrouvent également dans le puits de Saintes précité. Cette variété de bord paraît typiquement régionale ; elle semble réservée à des cruches de taille plus grande que la précédente, puisque la même différence de taille entre les deux types s'observe dans le puits de référence. Cette forme est particulièrement bien représentée dans un atelier céramique découvert à Saintes, dans la fouille dite des Ateliers Municipaux : voir M. Rouvreau, Archéologia, no 79, février 1975, fig. p. 39. Après comparaison d'échantillons, grâce a M. Rouvreau, nous ne pouvons cependant affirmer que les pièces 12 el 13 aient bien cette origine.

14. Grande cruche à pied annulaire évidé, très incomplète (on ne possède rien des parties supérieures, col et anses). IDiam. max. $40 \mathrm{~cm}$. Terre très tendre, grise à cocur, brun clair en surface, pâte chamottée et à dégraissant assez fin, fait en partie de débris de coquillages. Dans la partie inférieure, la paroi a, lors de la cuisson, gonflé en formant des cavernes. Trouvée à l'angle n.-e. du sarcophage ; décapitée par la pelleteuse.

Étant donné la taille, cette cruche devait avoir deux anses. D'après le galbe élancé et. la forme du pied, elle pourrait être rapprochée de la forme Gose 414, datée de l'époque de Claude.

15. Vase caréné à levre débordante sensiblement horizontale. H. 9,5; d. max. 9,8 cm. Terre gris clair, plus foncée en surface, à dégraissant grossier (nombreux éléments disparus formant des (reux plus ou moins grands) et particules de mica. Fabrication assez grossiere, le bord est ovale et non horizontal. Presque complet.

14 Voir notamment un exemplaire de mème matière, avec décor barbotiné différent el étranglements nettement moins accentués, au Musée de Saintés : F. . . 


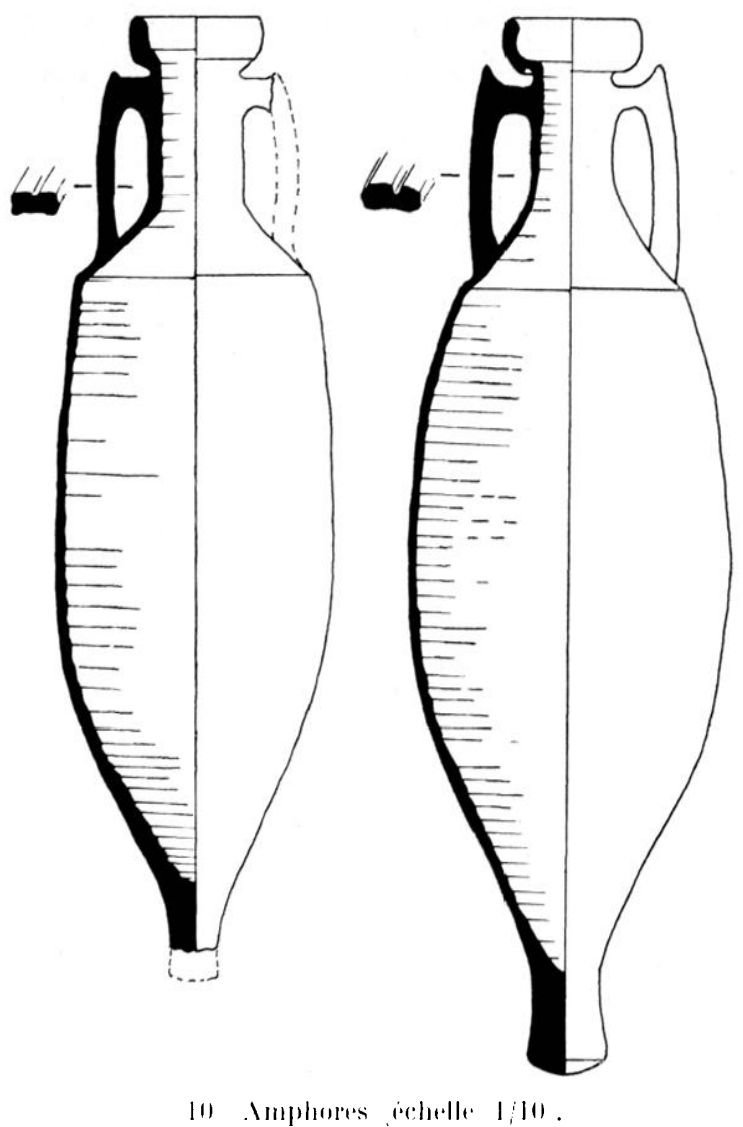

In exemplaire de plus grande laille mais de mìme forme el, semble-t-il, mème matière, dans le

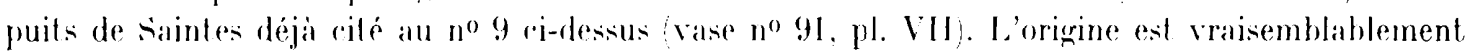
commune.

16. Vase ovölde à bord droit légerement ivase. II. 9,5; d. $8,2 \mathrm{~cm}$. Terre beige fine engobe gris fer a particules de mica. Presque complet.

Cin exemplaire de plus grande faille el orné a la rouletle. mais strictement de mème forme, dans

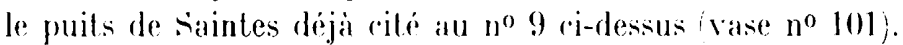

*17. Vase sensiblement de mème forme que le précédent en framents nombreux nayant pas permis une reconstitution (d. col: 11 rm. pied : 7 ( $m$ ) ; lerre tris tendre, grise.

I'n fragment de bord de mème forme d. 10 ('m) en terre brun rosé, a particules de mica, a élé recueilli dans les déblais: on ne peut dire si la cassure était fraiche; on ne le retiendra donc pas dans l'inventaire du mobilier funeraire. Il en est de mème de quelques framents d'autres poleries.

Imphores (figr. 10).

Amphore a anses "bifides " a coude formant un angle vif. leve en bourrelet. H. I00 cm. Céramique brun clair. grise a cour par endroits, aver couverte rose saumon par endroits (surtout dans la partie supérieure et pailleltes de mira; enduil brun à l'intérieur.

lutre amphore. meme forme. II. conservée 90 cm.. mais la pointe est incomplete. Courerte asse\% uniformément rose saumon, dégraissanl quarlzeux, pailletles de miral.

Trourés le long de la paroi ouest du sarrophatge.

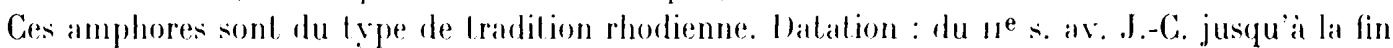
du ${ }^{\text {er }}$ sione apress. selon les éments rassembles par J.-P. Joncheray, Essai de classificalion des 

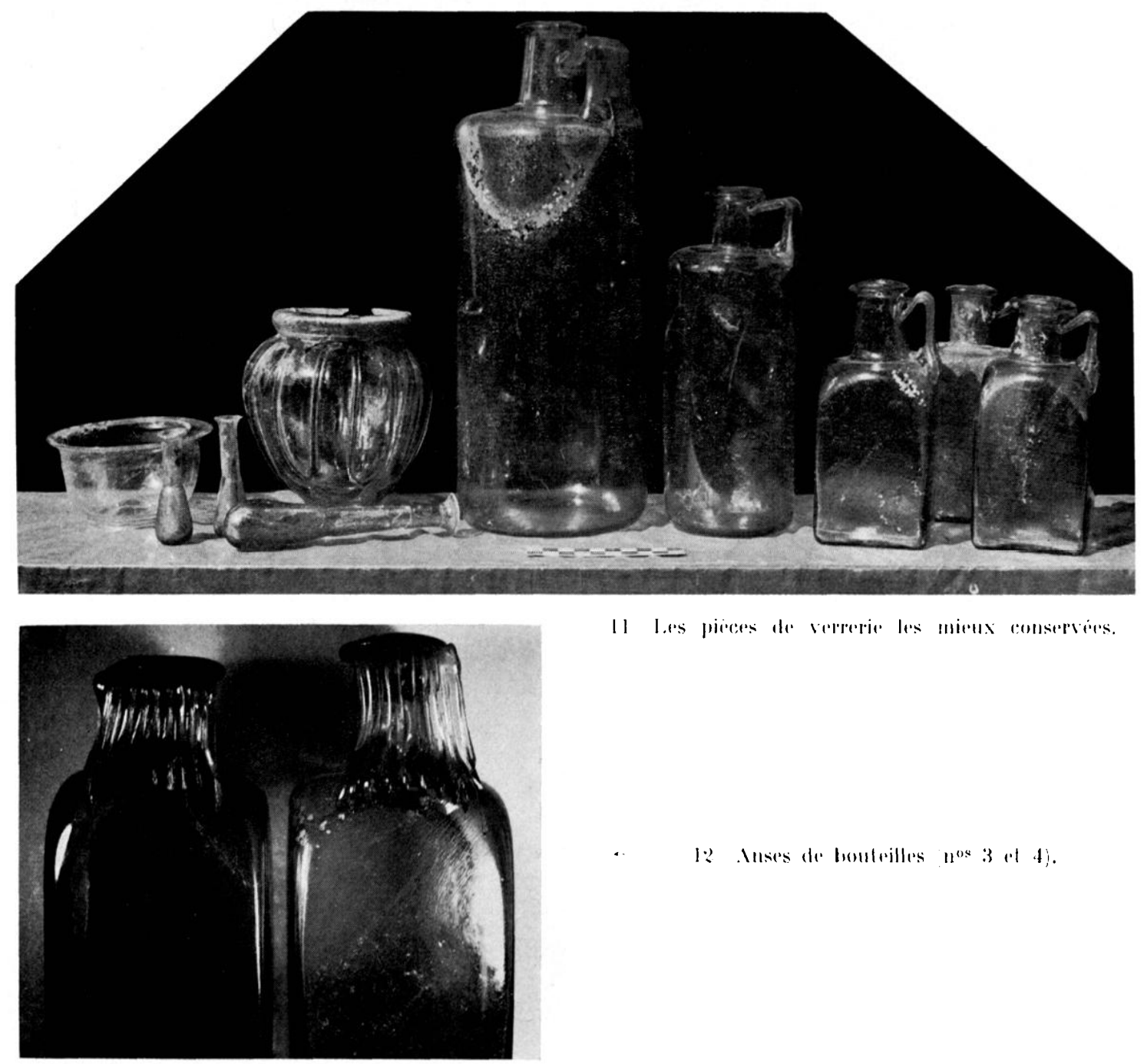

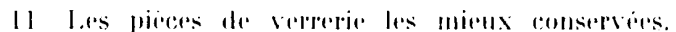

amphores decomerles lors de fonilles soms-marines. (iap. 1971 ; of. en particulier les nos 2 et 3 de la pl. V, provenant de l'épave du bramont $B$.

Mais les levres des deux exemplaires de Niort sont cependant diflérentes de celles des types de comparaison; elles se caractérisent par leur forme en bourrelet a l'exlérieur et leur profil vertical s'incurvant comme la paroi d'une coupelle à l'intérieur ; c'est ce dernier détail que nous ne retrouvons pas ailleurs, sauf sur des framments decouverts a une vingtaine de kilometres de Yiort, a lisseau (en bordure de la voie romaine venant de saintes et se dirigeant vers Cantes et. Ingers, en passant a l'ouest de Niort). Il y a la certainement une question d'origine qui reste à resoudre.

\section{Verrerie (fig. 11).}

L'étude est principalement fondée sur la rassification typologique et ahronologique. fournie par (: Isings, Roman glass from daled finds, (ironingen, Djakarta, 1957 (= Isings). Il a paru cependant intéressant de rappeler les réferences a l'ouvage de Morin-Jean. La verrerie en Gaule sous l'Empire romain, laris, 1913 ( = Jorin-Jean) et pour pallier la pauvreté de l'illustration de l'ouvrage de li. Isings, de mentionner parfois des exemplaires 
216

PIERRE-HENRI IITARD
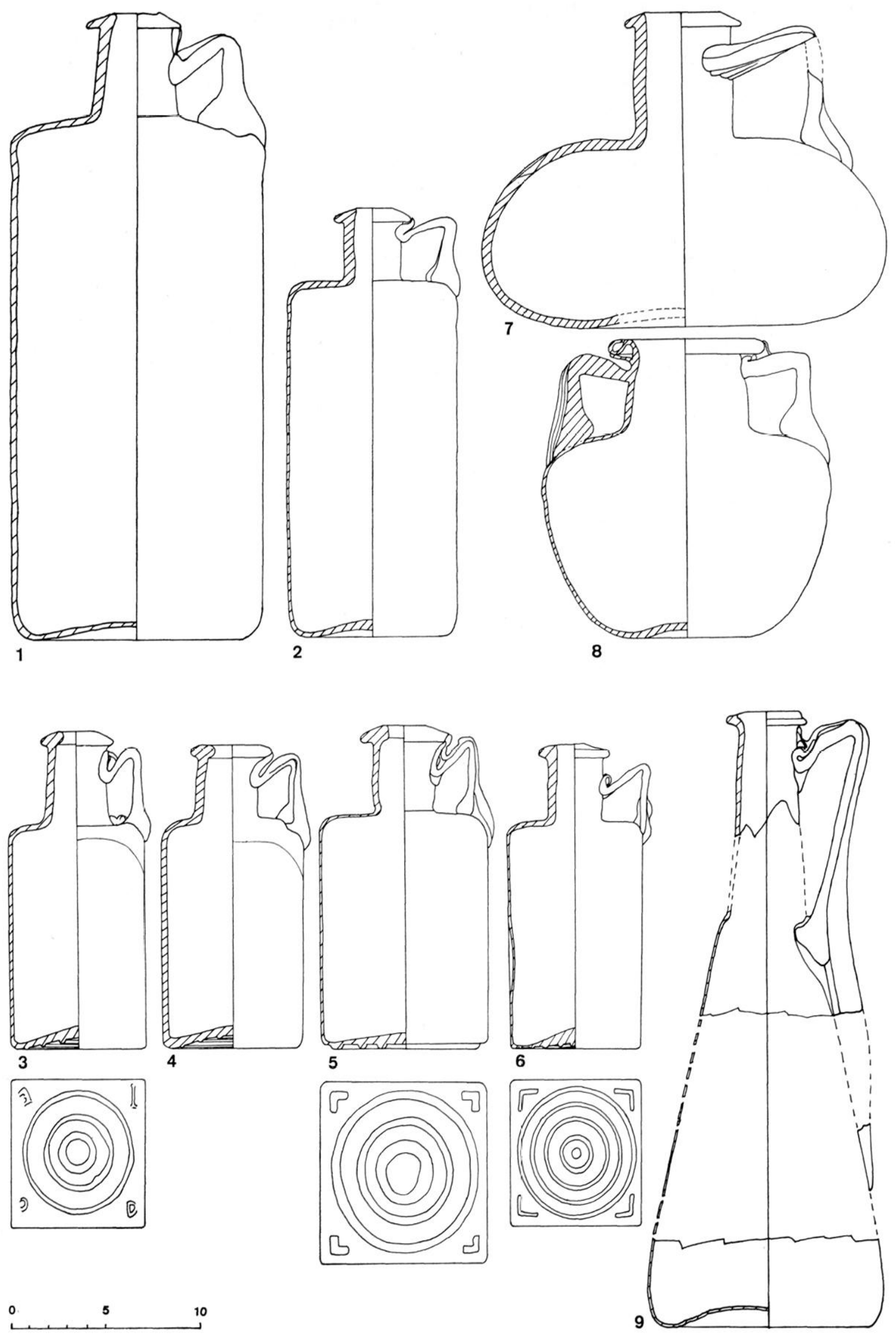

IV Verrerio. 
appartenant à des collections ayant fait l'objet de catalogues : O. Hoppelfeld, Römisches und Fränkisches Glas in Köln, 1966 (= Cologne); M. Vanderhoeven, Ierres romains (I-III siècle) des Musées Curlius et du V'erre à Liège, 1961 (= Liège); E. Wilhelm, La verrerie de l'époque romaine au Musée d'histoire el d'arl. Luxembourg, 1969) (= Luxembourg). Enfin, grâce à l'amabilité de l'auteur, nous arons pu consulter le mémoire de maîtrise de Ch. Gendron, La verrerie gallo-romaine sur le golfe des Piclons, 1970 ; nous nous y référerons parfois (= Gendron). Les numéros d'ordre renvoient aux pl. IV et $V$, sauf ceux affectés d'un astérisque (pièces non reproduites).

1. Bouteille cylindrique haute, a anse formée d'un ruban de verre à 13 nervures, coudé à angle droit (et mème aigu). H. 30,5) d. 13 cm. Verre bleu verdâtre. Intacte. Forme Morin-Jean 8; Isings 51b. Cf. Cologne, pl. 191 ; Liege, $n^{0 \%} 72.73$. - Les principaux exemplaires connus datent de la deuxième moitié du ier siècle : nombreux exemplaires à Pompéi en particulier, mais cerlains exemplaires datent du ${ }_{11}{ }^{\mathrm{e}}$ siècle. Cet exemplaire est un des plus grands exemplaires connus (un plus grand, cependant : $36 \mathrm{~cm}$ dans la sépulture de l'Ilot-les-Vases, de Nalliers. Vendée, sur laquelle nous reviendrons plus loin ; cf. Gendron, p. 27).

lin dépòt intérieur au niveau de l'épaulement laisse penser que la bouteille était couchée, fond légèrement soulevé, et qu'un liquide avait séjourné dans cette partie du récipient.

2. Bouteille mème forme que la précédente, anse à 7 nerrures. H. 21 ; d. $9 \mathrm{~cm}$. Verre même couleur, présentant sur un còté quelques bulles de tailles diverses (la plus grande $37 \mathrm{~mm}$ ). Félure au niveau du col et de l'épaulement.

In dépòt intérieur laisse penser que la bouteille était inclinée presque à l'horizontale.

3. Bouteille à panse prismatique de section carrée, à anse du mème type que les précédentes, a 10 nervures (fig. 12); fond orné de trois cercles concentriques et de lettres aux angles, en relief : I E C I) (en faisant tourner la bouteille dans le sens positif), I et D) droits, E oblique et C incertain (serait à l'envers). On ne sail où faire commencer la légende. Fond et panse faits dans un moule. H. 15,5 , còté $7,2 \mathrm{~cm}$. Verre bleu verdâtre, présentant quelques bulles (jusqu'à $7 \mathrm{~mm}$ de long) et des petits creux formés par un jet de sable (?). Intacte.

Forme Morin-Jean 14 ; Isings 50a. Cf. Liegre nos 51 à 56, Luxembourg no 77 et s. Apparaissant au milieu du ${ }^{\text {er }}$ siècle ; nombreux exemplaires datables de la période Claude-Yéron el des Flaviens. mais le type persiste jusque vers le milieu du ${ }^{2}$ es. dans la mème qualité de matière (et au-delà dans une qualité moindre).

4. Bouteille de mème forme que la précédente, anse à 9 nervures (fig. 12), même décor au fond, issu du même moule. II. 14,8; còté $7,2 \mathrm{~cm}$. Verre de mème couleur et mèmes caractéristiques. - Intacte.

In dépòt dans un des angles supérieurs de chacune de ces bouteilles laisse penser qu'elles étaient couchées, fond légèrement soulevé.

5. Bouteille de même forme que les précédentes, anse à 6 nervures; fond orné de trois cercles concentriques et de petites équerres aux angles, en relief. Fond et panse moulés. 11.16 ; còté $8,5 \mathrm{~cm}$. Verre vert clair, sans bulle. - Reconstituée (avec des manques). Fabrication différente, mais d'aussi bonne qualité que pour les nos 3 et 4 .

6. Bouteille de mème forme que les précédentes, anse à 9 nervures; fond orné de quatre cercles avec un point au centre et de pelites équerres aux angles. en relief. Fond et panse moulés. H. 14,5; còté $6,8 \mathrm{~cm}$. Verre vert jaune. - Fèlée et écornée.

Fabrication négligée : col irrécrulier, anse présentant une coulure par-dessus les nervures, irrégularité à un còté de la panse.

7. Bouteille sphérique aplatie; paroi épaisse (jusqu'à $6 \mathrm{~mm}$ ); anse de mème type que sur les 
précédentes à 7 nervures. Verre bleu verdâtre. II. $15 \mathrm{~cm}$ environ ; d. $22 \mathrm{~cm}$. - Importants fragments permettant une reconstitution graphique.

Forme non répertoriée, ni par Horin-Jean. ni par C. Isings. Mais un exemplaire comparable, plus aplali cependant, figure dans le mobilier de la sépulture de l'llot-les-Vases de Talliers. déja citee. Voir Archéslogia, no 68 , mars 1974, p. 39 (fig. du haut, à dr.).

8 . Lrne a panse globulaire à deux anses opposées de même type que les précédentes. à 10) nervures; fond concave. II. présumée $16 \mathrm{~cm}$ environ : d. $15 \mathrm{~cm}$. Verre vert, assez clair, avec bulles. Reconstituée partiellement (partie supérieure et fond).

Forme Morin-Jean 3 ; inconnue de Isings.

In exemplaire très voisin (un peu plus sphérique) à Viontboucher (Creuse), dans un groupe de tombes a incinération (coffres en pierre) ayant livré par ailleurs un grobelet à une anse, forme Isings 37, datable de la seconde moitié du ${ }^{\text {er }}$ siècle (Gallia, XX1. 19ï3, p. 491, fig. 11). Deux exemplaires ausisi dans l'importante sépulture de saint-Médari-des-Pris, datable du ${ }_{1} \mathrm{e}$ siècle (Gendron. p. 26).

9. Carafe a panse conique, a anse longue avec nervure centrale en fort relief et se prolongeant au-dela du point d'attache principal; fond concave. II. présumée env. $29.5 \mathrm{~cm} ; \mathrm{d}$. max. $13 \mathrm{~cm}$. Verre bleu clair franc au col, bleu vert clair pour le reste (panse et anse). - - Très incomplete.

Forme Yorin-Jean 57. Isings. 5)a. Cf. Cologne. pl. 29. La forme apparait au milieu du Ier siecle el est tres commune au dernier quart de ce siècle. In exemplaire en particulier (mais aver une attache d'anse différente, comme à Cologne) dans la riche sépulture de Berlingen (Limbourg. Belgique), sur lacquelle nous reviendrons et qui est datable de l'époque flavienne ${ }^{15}$.

10. I'rne ovoüde à pelit pied et embouchure à ourlet convexe. Panse ornée de nervures lauxquelles correspondent à l'intérieur des saillies moins prononcées) se réunissant deux par deux à la base ( 7 doubles nervures, une simple). 11.13 ; d. max. 13 cm. Verre bleu clair franc, avec de tries petites bulles. Reconstituée (quelques manques sur un còté).

Forme Isings 67\%. Cf. Liege $\mathrm{n}^{0} 102$. Luxembourg $\mathrm{n}^{0} 52.2$.

La forme est datable de la fin du $1^{\text {er }}$ et du II $^{\mathrm{e}}$ siecle. Mais cet exemplaire differe des exemplaires de comparaison d'une part par son bord convexe el par les nervures se rejoignant deux a deux it lit base.

11. I me mème forme que la précédente, mais embouchure à ourlet concave. mềne décor. I1. présumée : $13 / 14 \mathrm{~cm}$. Verre de couleur un peu plus verte.

12. Ampoule à goulot évasé et bord coupé aux ciseaux, à parois trìs minces (moins de $1 \mathrm{~mm}$ ), ornée au col et à la panse de filets circulaires gravés. H. présumée $9 \mathrm{~cm}(?) ;$ d. max. $7,8 \mathrm{~cm}$. Verre jaune vert clair. - Reconstituée incomplètement; on ne sait en particulier si le fond comportait un pied annulaire ou non (cette dernière solution paraissant cependant plus probable).

Forme Morin-Jean 40) (voir en particulier : fig. 108. p. 93, mème couleur); Isings 92 ou 104. Morin-Jean date ce type du Romain II ( $\mathrm{III}^{\mathrm{e}} / \mathrm{I}^{\cdot} \mathrm{e}$ s.), mais, pour un type voisin (forme 37), place le début de ce dernier au $\mathrm{I}^{\mathrm{er}}$ siècle. Les spécimens mentionnés par C. Isings pour la forme 92 (peu

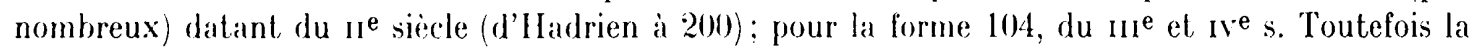
forme présentée par chacun de ces auteurs est plus sphérique qu'ici.

13. Gobelet à bord coupé aux ciseaux légèrement évasé, pied annulaire plein, paroi mince $(1 \mathrm{~mm})$ ornée de filets circulaires gravés et d'une petite gorge encadrée de filets larges meulés (?). I1. minimum $14,5 \mathrm{~cm}$; d. bord 7,3. Verre bleu verdâtre clair. Reconstitué incomplètement.

Forme Morin-Jean 109, voir en particulier : fig. 190, p. 141 ; Isings 34 (mais à base massive). Type créé dans la seconde moitié du ${ }_{1}^{\text {er }}$ s. mais qui survit jusqu'au ${ }^{*}$ s. Un exemplaire dans la

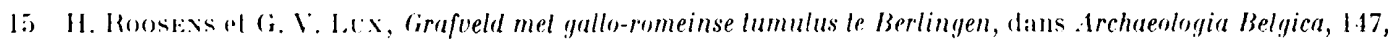
Iruxelles, 1973. 


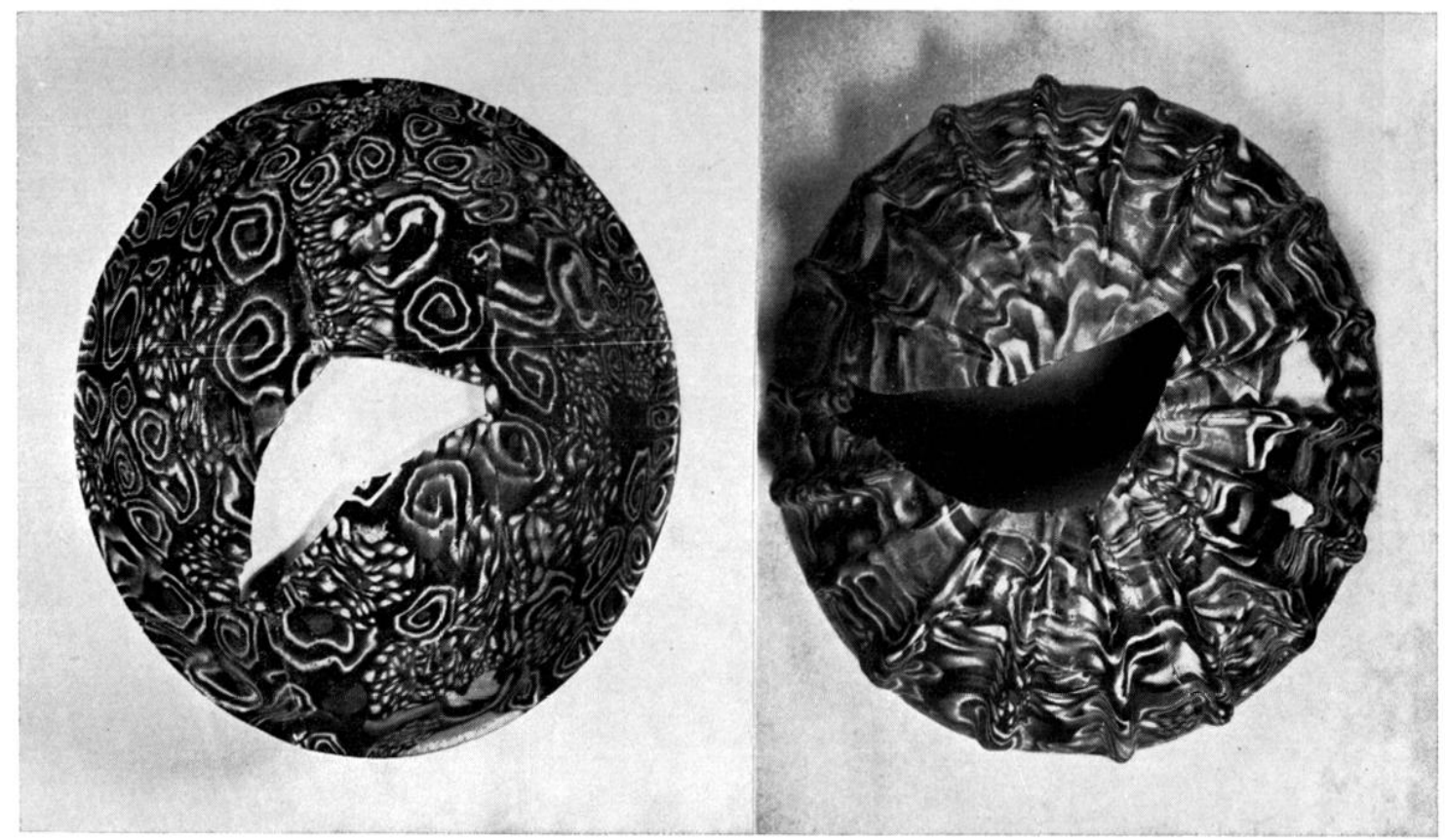

13 Phiale en verre millefiori n $^{\circ} 24$; : interieur et exterieur.

sépulture de l'Ilot-les-Vases, considéré comme de la fin du er siècle (Ch. Gendron, Archéologia, $n^{0}(88$, mars 1974, p. 43), figg. du haut, ext. droite), bien que la sépulture elle-mème soit un peu plus tardive.

14. Gobelet à bord droit coupé aux ciseaux et souligné d'un filet circulaire gravé ; apode, fond concave, paroi trìs mince (1/2 $\mathrm{mm}$ ), ornée de 12 dépressions étroites (résultant d'un pincement de l'intérieur). II. incertaine : env. $14 ; \mathrm{d}$. bord $9 \mathrm{~cm}$. Verre vert jaune clair. - Très incomplet.

Morin-Jean ne parle de wobelet orné de dépressions qu'à propos de sa forme 109 (à pied annulaire). Cf. Isings 32, différent par la forme du bord (évasé) et le genre de dépressions (quatre très ouvertes). ... Les exemplaires mentionnés les plus anciens datent de la deuxième moitié du $1^{\text {er }}$ s., d'autres sont des III $^{\mathrm{e}}$ et $\mathrm{IV}^{\mathrm{e}}$ siècles.

15. Plat dit " cylindrique " a paroi basse, en fait oblique, à bord ourle formant anneau circulaire creux, pied annulaire creux. H. $2,4 \mathrm{~cm} ; \mathrm{d}$. bord $18 \mathrm{~cm}$, pied $15,5 \mathrm{~cm}$. Verre jaune très clair. - Fond intact et petite section de bord recollée.

Forme ignorée de Iorin-Jean; Isings 48 . Deux lieux de trouvaille seulement mentionnés, tous deux du $\mathrm{I}^{\mathrm{er}}$ sièrle. le second plus précisément d'époque flavienne : un «service » de quatre plats, dans un tumulus gallo-romain is Vervo\% (commune de Clavier, prov. de Liège) (= Liège 47 à 50).

16. 17, "18. Plals mème type, mèmes dimensions (saul pour un dont la hauteur est un peu plus élevée : 2,7 ('m) ; verre mème couleur.

lin fragments difficiles it classer par individu en raison de la similitude des dimensions, les différences de grosseurs des bords et des pieds annulaires n'étant pas déterminantes, car elles varient d'un point ì un aut re du mème plat. Le nombre de trois est un minimum; un quatrième est possible, dont le diamietre du pied serait de 17 rm environ. si on fail abstraction de cet exemplaire (un je en fait, mais douteux), on notera le rapprochement a faire quant, an nombre avec la découverte de Vervoz ci-dessus mentionnée.

19. Bol a paroi convexe, live evasce a bord arrondi, pied ammulaire reux. II. moyenne 5,5; d. $11,2 \mathrm{~cm}$. Verre vert tris prile. - Intact. 
Forme ignorée de Yorin-Jean ; Isings 42 . Cf. Liège nos 41 à 43. Non antérieure aux Flaviens (70 env. par conséquent) et se maintenant durant le $\mathrm{II}^{\mathrm{e}} \mathrm{s}$.

20. Bol même forme que précédent. II. présumée 5 cm env., d. 10,7 cm. Verre jaune vert clair. - Reconstitué partiellement (bord et fond).

21. Bol mème forme que précédents. II. présumée $4 \mathrm{~cm}$ env.; d. $8, \bar{c} \mathrm{~cm}$. Verre vert clair. Reconstitué partiellement (bord et fond).

22. Bol même forme que précédents, mais lèvre moins évasée. II. incerlaine ; d. 11,5) (m. Très incomplet.

23. Coupelle à paroi très fine $(2 / 10 \mathrm{~mm})$ d'une forme générale voisine de celle des bols précédents, mais à pied très mince et droit. II. moyenne $3 \mathrm{~cm}$ (irrégulière); d. bord $8 \mathrm{~cm}$. Verre vert, non transparent, à bulles trés serrées formant granulation en surface à l'extérieur ; irisation dorée à l'intérieur. - Incomplète.

24. Phiale, ou coupe, cotelće. II. 4/4,5 cm ; d. 14,6 cm. Verre millefiori, imitant le marbre ou l'agate : fond vert avec veines et taches irrégulières jaunes et taches rouges plus clairsemées (figg. 13). - Reconstituće presque complètement, un fragment était encore en place dans la sape.

Le verre millefiori comprend plusieurs variétés, suivant la nature des inclusions que l'on enfonçait dans la masse unie de liaison. Ici le verrier a manifestement pratiqué de la façon suivante : préparation de deux catégories d'éléments : les uns formés de plaquettes minces, jaunes, enroulées autour d'un bâtonnet rouge; ; les autres de bâtonnets ou lanières de sections plus ou moins régulières, jaunes, rassemblées en petits fagots autour d'un bâtonnet rouge ; débitage de ces rouleaux et fagots en petites tranches ; application de celles-ci sur une plaque de verre vert et compression dans un moule à température convenable, ce qui aboutit à certaines déformations des motifs, tout en donnant sa forme intérieure et extéricure à la coupe. Les éléments jaunes et rouges restent opaques.

Forme Morin-Jean 68 ; Isings 3a. La forme qui existe en verre monochrome (bleu, vert, brun) est typiquement du $\mathrm{I}^{\mathrm{er}}$ siècle, même si elle déborde un peu sur le $\mathrm{II}^{\mathrm{e}}$. Des exemplaires en verre millefiori sont cités dans des contextes allant de l'époque augustéenne à l'époque flavienne (Pompéi en particulier).

Des fragments de technique semblable ou voisine ont été trouvés sur divers sites de la région, à l'Ilot-les-Vases de Nalliers, à Saint-Médard-des-Près - en dehors des sépultures mentionnées dans le présent article - à Saint-Benoit-sur-Mer (Vendée) (Gendron, p. 54-55), mais aussi à Poitiers, à Sainte-Eanne (Deux-Sèvres) (renseignements Ch. Gendron). Il y avait donc un courant d'approvisionnement pour ces verreries spéciales d'origine lointaine (italique ou en tout cas méditerranéenne).

*2:5. Phiale même forme, même technique, mêmes dimensions que la précédente. — Déchiquetée par la pelleteuse, reconstituée pour une large part.

26. Patère à manche, ou trulla, manche plat s'élargissant aux deux extrémités, en verre bleu foncé ; coupelle en verre bleu clair barré d'une large veine brune, et orné à l'extérieur d'un filament blanc en relief (en spirale?). A l'extrémité (extérieure) du manche, empreinte, mal venue d'un cachet ...VS FEC en faible relief ( $\mathrm{V}$ incertain et $\mathrm{S}$ à l'envers).

Dimensions. Manche : long. $6,2 \mathrm{~cm}$; épais. $0,3 \mathrm{~cm}$; coupelle $: \mathrm{d} .7 \mathrm{~cm}$; la profondeur n'est pas connue, mais parait relativement importante. Le manche est complet, la coupelle représentée seulement par quelques fragments qui ne permettent d'avoir qu'une idée très approximative de la forme. 

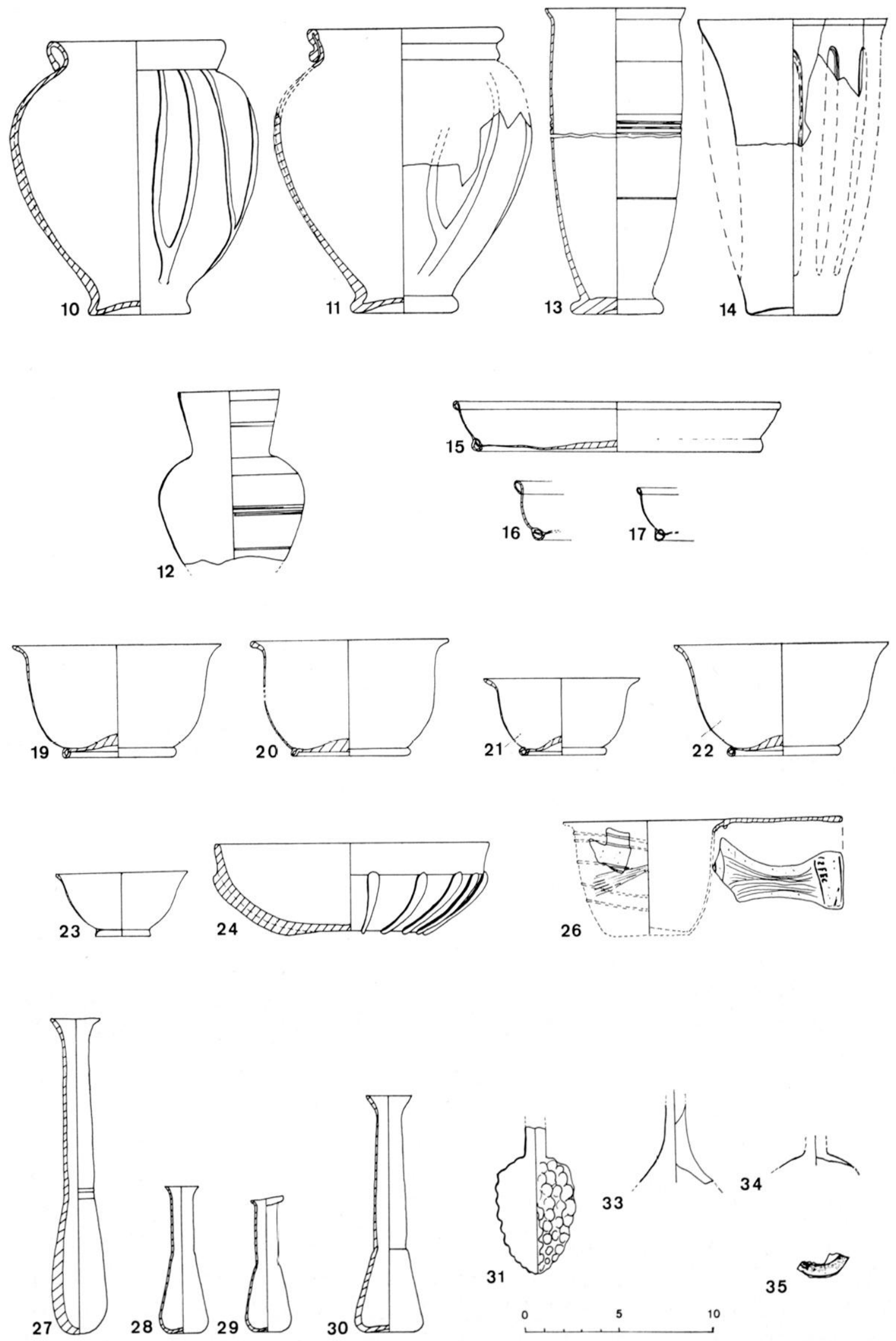

I. Verrerie. 
Forme (f. Morin-Jean 136-137; Isings 75) i-b. L'insuffisance des éléments conservés ne permet pas de trancher entre les deux formes de références. qui diffèrent principalement par la profondeur relative la forme profonde parail cependant la plus probable d'apris un des fragments.

Le meilleur exemple de comparaison est fourni par deux patieses en verre bleu, aver décoration analogue, trouvées dans la sépulture de Berlingen déja citée (a propos du no 9 ci-dessus ; cf. op. cil.. fig. $16, n^{\circ} 6$ et 7 . Ces exemplaires n'ont pas de pied. mais sont rependant trìs areux. comme la forme Isings 7i) b.

Peu d'exemplaires de ces formes mentionnées par G. Isings, certains de l'époque flavienne (Pompéi) ou de la fin du er s.. d'autres plus tardifs. Ilais un autre rapprochement est plus intéressant : il concerne une carafe de la mème technique de décoration sur verre bleu également, tronvée à Cologne et datée du i ${ }^{\text {er }}$ siècle (Cologne. pl. 39).

27. Fiole tubulaire, dite lacrymatoire, en fait balsamaire; étranglement léger dans la moitié inférieure el fond arrondi (ne permettant pas la position debout), lèvre évasée, paroi tris épaisse près du fond. H. 15,2; d. max. $3 \mathrm{~cm}$. Verre bleu verdàtre. Complète, col recollé.

Forme non distinguée par Morin-Jean ; Isings 8 . Cf. Liège nos 5, 6, 8 ; Luxembourg, nos $17 \mathrm{el}, 20$. Couvrant tout le $\mathrm{I}^{\mathrm{er}}$ sieccle; nombreux exemplaires à Pompéi, mais on en trouve encore au $\mathrm{II}^{\mathrm{e}} \mathrm{s}$.

28. Petite fiole, à panse piriforme, fond concave, col à lèvre évasée, représentant la moilié de la hauteur totale. II. 7 ; d. $\max .2,5 \mathrm{~cm}$. Verre bleu clair. Intacte.

Forme Morin-Jean 21 ; Isings 28 a. Les exemplaires datés vont essentiellement de Claude i la fin du I $^{\text {er }}$ siècle.

29. Petite fiole, mème forme que la précédente, mais col à lìvre en bourrelet (irrégulier). H. $\max .6,5 ;$ d. $\max .2,5 \mathrm{~cm}$. Verre jaunàtre. Intacte.

30. Fiole à panse piriforme, col à lèvre évasée représentant environ les deux liers de la hauteur totale. H. 11,$5 ;$ d. max. : $3,7 \mathrm{~cm}$. Verre bleu verdâtre. Fond brisé lors de la découverte, dans le sarcophage.

Forme Morin-Jean 21 ; Isings 28 b. Mème datation que précédente. étendus.

Ces quatre balsamaires (nos 23 a 26 ) présentent à l'intérieur des dépòts bruns plus ou moins

31. Petit vase (balsamaire?) moulé, en forme de grappe de raisin, à col cylindrique lisse. II. présumée 7 ou $8 \mathrm{~cm}$., d. max. $4,2 \mathrm{~cm}$. Verre bleu soulenu. Incomplet : manquent sommet du col et parties opposées de la panse. Ces manques ne permettent pas de savoir si ce vase possédait ou non des anses.

Forme : cf. Morin-Jean 131 ; cf. Isings 78 e ou 91 a. Morin-Jean ne mentionne que des exemplaires tardifs, grénéralement de plus grandes tailles et possédant deux anses. C. Isingss cite un exemplaire de taille comparable à celui-ci el sans anse $(78$ e) à Pompéi. Cependant un exemplaire plus petit $(\mathrm{h} .5 \mathrm{~cm})$ et avec anses est connu dans le mobilier funéraire de l'Ilot-les-Vases, déjii cité (Gendron, p. 40), datable du début du ${ }_{11}{ }^{\mathrm{e}}$ siècle.

"32. Autre exemplaire probablement issu du mème moule ; verre vert jaune clair. - Représenté seulement par trois petits fragments de panse $\left(2 \mathrm{~cm}^{2}\right.$ au total $)$.

A titre ce comparaison. signalons l'existence au Vusée des Antiquités Nationales de deux petites bouteilles carrées ornées de têtes d'enfants, moulées (issues manifestement du mème moule). l'une en verre bleu, l'autre en verre marron, trouvées à saintes, probablement ensemble (Inv. 24.641, 24.642).

33. Petite fiole, forme incertaine, en verre bleu vert clair. - Représentée par un petit fragment avec base du col (d. $11 \mathrm{~mm})$.

34. Autre fiole, forme incertaine, en verre bleu vert clair. -- Représentée par un fragment avec partie du col (d. $12 \mathrm{~mm})$.

35). Petite fiole de forme incertaine; verre vert semblable à celui du no 32 , veiné de marron (fragment de col) et avec bande rapportée marron (fragment de panse). Deux fragments. 
Diners.

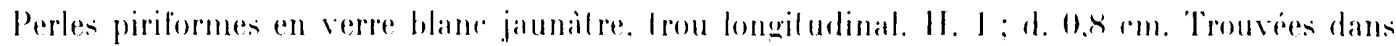
le sarephatre, an niveau inferieur du crane d'apres les indiations des ouvriers : au nombre de b) ou 6, mais nous nien avons en en mains que deux.

Ces perles onl la forme de pendelonges et devaient avoir éte suspendues verticalement a une armateur de métal appartenant soil à un collier, soil a des boucles d'oreilles; mais on ne nous a simnalé aucune trare d'une lelle armature.

Perle allongée de section hexagonale. en verre bleu vert. $1.2 .2 \mathrm{~cm}:$ : l. exlér. (aux arètes) $1.1 \mathrm{~cm}$. Cet exemplaire unique nous a ét remis aver l'ensemble de céramique el de verrerie provenant de la fouille clandestine et par conséquent en principe du coflre. II y a tout lieu de penser qu'elle enl rail dans la composition d'un collier dont le reste ne nous est mallheureusement pas parvenu.

Paletle a fard de forme losangée en calcaire compact, de couleur crème. comportant une petile cuvette ovale. L. 9: : I. 5.5): (2p. 1/1.5) rm. Face supérieure polie. face intérieure taillée de façon sommaire.

Piece de métal en forme de croix, romprenant au centre un élément bombé en bronze sur lequel sont adaptées quatre branches en fer. dont la tongueur ne parail pas avoir dépassé 4 cm. L'usage de cet objel ne nous apparail pass. Il provient de la fouille clandestine el on peut se demander sil n'appartenait pas atu colfre, par exemple pour constituer une grille sur une ouverture (?).

\section{Intereit de la sépullure.}

L'étude des différents iléments constituant le mobilier de cette sépulture permet une datation assez precise de celle-ci : les monnaies, emises toutes deux en 41 ou au rours des années suivantes, fournissent un lerminus post quem; les pièces de céramique sigillée les mieux datées, celles portant des estampilles ( $\left.\mathrm{n}^{\text {os }} 1,2,3\right)$, ne dépassent pas l'époque flavienne; deux des céramiques à parois fines restent sensiblement dans les mèmes limites, l'une (no 9) étant en principe un peu plus tardive que l'autre $\left(\mathrm{n}^{0} 11\right)$; les deux cruches (nos 12 et 13) et les deux pots de ceramique grise se retrouvent dans des contextes dates de la même époque. par des pièces de sigillée; les amphores, par leur forme atteignent, la mème limite

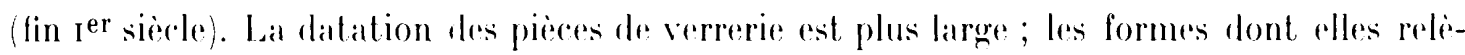
vent cependant couvrent principalement la ?e moitic du jer sière, mème si elles comportent des prolongements all ${ }^{\mathrm{e}}$ siecle (et plus rarement au-rlela). Les plats (nos 1 jo à 18), la patère $\left(n^{0} 26\right)$ se retrowent dans des contextes flaviens. C'est vaiment de cette époque flavienne, ou si l'on préfère des années 70-95), qu'il faut dater cette sépulture. Rien ne rend plus vraisemblable une datation plus récente.

Or à cette époque, il est bien connu que l'incinération est le rite largement dominant en Gaule. Dans la (iaule septentrionale (France, Belgique, Rhenanie), région pour laquelle on dispose d'un répertoire et d'une cetude de synthèsele. les cimetiires ou tombes isolées a inhumations représentent i) seulement du total des sites funéraires connus pour la

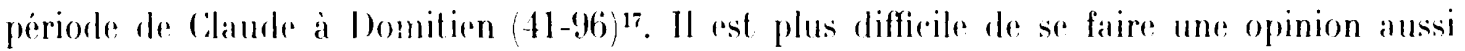

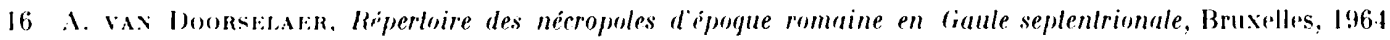
2 vol. , Les nécropoles dépoque rumaine en Ciaule seplenlrionale, Inisserlaliones archeoloyicae (iandenses, vol. $\mathrm{X}$; Bruges, 1967.

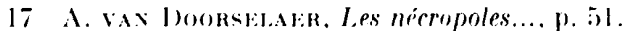


précise pour le reste de la Gaule ; toutefois les dépouillements auxquels nous nous sommes livés - notamment celui de la collection de Gallia montrent que, mises a part peut-itre certaines régions. la bourgogne en particulier, et en dehors de quelques cas isoles remontant, à la deuxième moitié du fer sièrele, les inhumations ne commencent rédlement à se développer qu'au I $^{\mathrm{e}}$ siècle (pour triompher ensuite à partir de la fin du III ${ }^{\mathrm{e}}$ sous l'influence du Christianisme). On roit dans ce developpement de l'inhumation un fait de romanisation (le retour à l'inhumation étant à Rome dù lui-même à des influences orientales), bien que. dans le Centre de la Caate, le phénomène puisse en fait correspondre à une persistance, ou une renaissance, de trarlitions celtiques ${ }^{19}$.

En tant qu'inhumation, la sépulture de Yiort-Bessines présente donc: un caractere peu courant, pour son époque. Le fait qu'elle comporte un sarcophage en renforce évidemment l'intérêt, rar le sarcophage, étant lié au rite de l'inhumation ${ }^{20}$. ne pouvait qu'ètre particulièrement rare à cette époque. De fait, en dehors des sarcophages ornés de la région

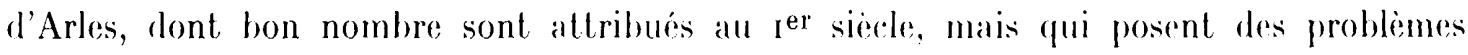
différents ${ }^{21}$, les sarcophages découverts en Gaule et dabables du der siècle sont extrèmement, rares. Sous ne pourons en retenir qu'un, découvert à lilermont-Ferrand aver quelques autres) en 1965), et que l'étude du malériel. d'après la photo publiée, permet de dater,

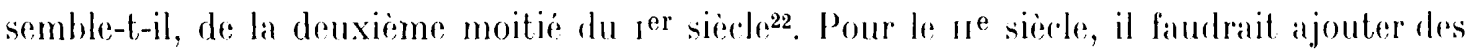

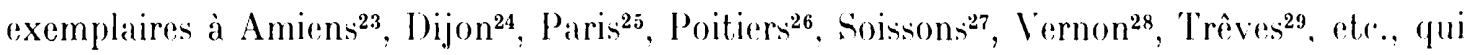
témoignent d'une romanisation progressive, plus particulierement sensible dans les villes. On voit done que, dans cette évolution, le sarcophage de Niort-Bessines prend chronologiquement, pour la baule Chevelue, une des toutes premieres plares.

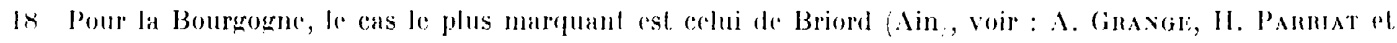

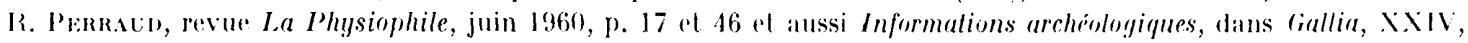

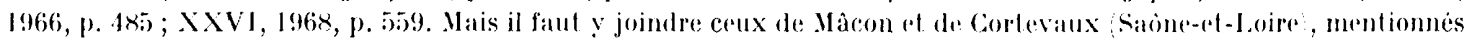
par les mêmes auteurs. Pour les cas plus isolés, cilons : Alise-Sainte-Reine (Alesia) (encore qu il s'agisse la dre sépultures d'enfants: : Galia, VIII, 1950, p. 15x; Camdebec-les-Elbeuf : Gallia, XXIN, 1966, p. 2666-268; Clermont-Ferrand :

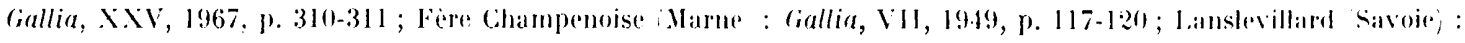
Gallia, XIX, 1961, p. 245-218; Haneon (IIte-Vienne, : Gallia $\mathrm{XV}$, 1957, p. 228-2:99.

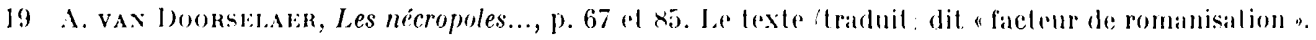

20 Bien quil existe quelques rares cas de sarcophages renfermant des incinérations a simpelveld limboure. Pays-Bas, à Weiden Cologne ; cf. A. vax Doorstiakr, op. cit., p. 157.

21 J.-J. HaTr, I.a lombe gallo-romaine, Paris, 19:1, p. 113.

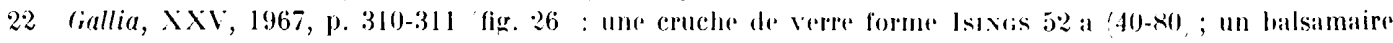

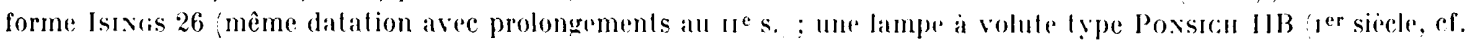
Nolice lechnique, T.C.F., n" 9, une cruche à ingobe blanc qui par sa forme proul ètre rapprochée des produclions d'un

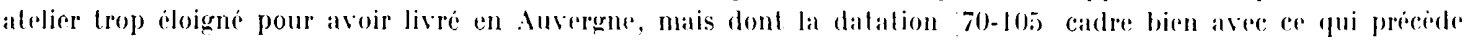

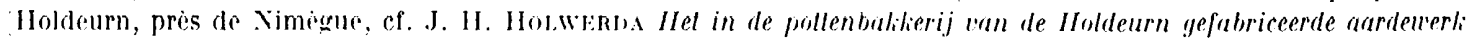

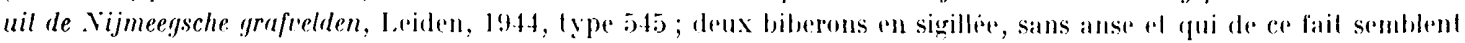

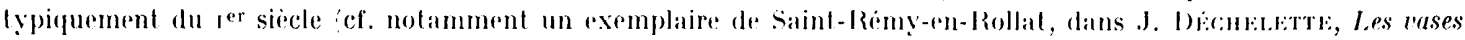
céramiques ornés de la tiaule romaine, 1904, I, 1. 45, fig. 2x. Yous drovons les indications concernant la cruche of les biberons à B. Ilofmann.

23) A. vax Doonshiale, Réperloire. 1I, p. 249; Gallia, 11; 1945, p. 133-134.

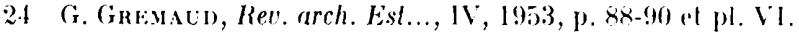

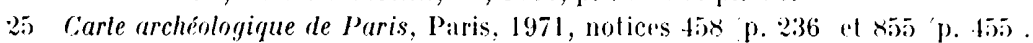

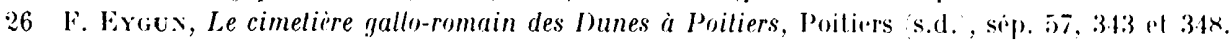

27 A. vax Doonstianer, Ripertoire, 1I, p. 135.

28 Gallia, XXIV, 1966, p. 262-263.

29) A. vax Doonsfican, Répertoire, II, p. 11:2-111. 
Au fait mème de l'inhumation an sareophage et dans un sareophage de grande taille s'ajoute labondance du mobilier déposé dans cette sépulture, pour en souligner limportance. On sait bien que les tombes gallo-romaines comportent grenéralement des élements mobiliers en métal, céramique ou verre. Lal plupart des fragiles pièeses de verreric présentés dans les musées ont naturellement une telle provenaneero. Et cela est vrai aussi bien dans les cas d'incinérations que dans aeux d'inhumations; le mobilier est plus partirulierement important au Haut-Lmpire det deroit semble-t-il uau fur et a mesure que lon s'avance dans le temps ${ }^{31}$. Quoi qu'il en soit, le nombre des pieces ne dépasse généralement pas quelques unites : six par exemple pour la sépulture en sarcophage de ClermontFerrand, deja cité (n. 2) 2 ). huil ou neuf outre l'urne cinéraire pour une incinération découverte à Pamproux (Deux-tiveres), non loin de Xiort ${ }^{32}$; a Poitiers, chef-lieu de la cite a la limite de laquelle se trouviat . Niort, sur 57 sépultures des rer au we sièles, il est vai) dont le mobilier a pu être le mieux olservé, 36 ne romportaient qu'une, deux ou trois pieces de mobilier céramique el verrerie essentiellement, non compris de toute facon les pièces de. monnaies). 16 en remportaient de quatre à neuf, cinq seulement plus de dix ${ }^{33}$.

Ici le nombre des objets déposés en offrandes non compris les perles de collier oud de boucles d'oreilles trouveses sur la défunte elle-mème et qui faisaient partie de la parure de celle-(i) dépasse an y compremant naturellement aussi bien les pièces intactes que celles simplement représentés par un ou deux fragments -- la cinquantaine : 19 pour la céramique, 35 pour la verrerie (dont il est vai plusieurs pièces de petite taille at de faible valeur, si ce n'est peut-être pour les parfums qu'elles pouvaient contenir). plus une perle en verre, vestige peut-être l'un collier complet, une palette à fard en pierre et les deux monnaies; et ces chiffres ne peuvent ètre considérés que comme des minima, puisqu'il n'est pas exclu que le second fouilleur clandestin ait pu découvrir et ronserver quelques pièces entières, dont on n'aurait alors aucune trace. Des sépultures gallo-romaines présentant des mobiliers l'importance comparable la qualité de certains objets en bronze compense parfois le nombre plus réduit au total) ont été décourertes an des régions de la (iaule aussi éloignées que la Narbonnaise : sépulture a auge (incinéralion) de Pignan (Hérault) s4 sans doute un peu plus ancienne que la nòtre et la Belgique : sépulture féminine à incinération de

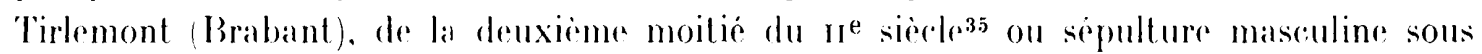
Lumulus (28 m de diametre) de Berlingen /Limboura) ${ }^{36}$ d'époque flavienne, comme ici.

D'autres exemples correspondant à d'autres régions pourraient certainement être donnés. mais c'est aver trois sépultures découvertes dans la région même, en Vendée, respectivement à 45, 30 et $18 \mathrm{~km}$ au nord-ouest de Niort-Bessines, à Nalliers (lieu-dit L'llot,

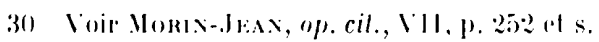

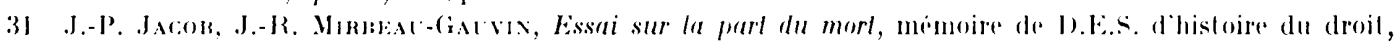
Iniversile de I)ijon, 1972, p. 3x.

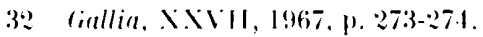

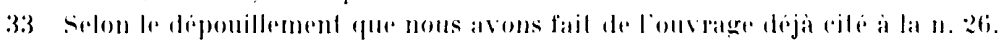

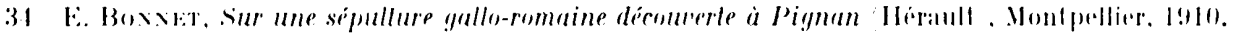

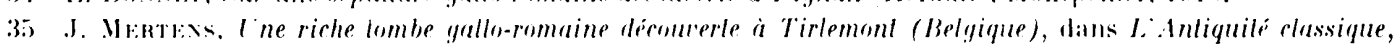

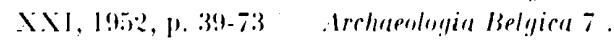

36 ()) ril., 11. 15. 
ou l'Isleau-les-Vases), a saint-Médard-des-Près sépulture dite a tort … "de la femme: artiste ") et Bonillé-Courdault ${ }^{37}$, que l'on peut faire les rapprochements les plus etroits :

dans les trois cas, il s'agissait d'inhumalions (lat derniere en sarcophage). comportant d'abondants mobiliers principalement des pieces de verrerie (5), "pres de 80 ". et 24 unités. respectivement). mais aussi de céramique (26 vases, 6 amphores. (i vases et 1 amphore, respectivement), ainsi que quelques autres objets, le lout dispose autour de la sépulture. dans un coftre ou a nu. lans les trois ras aussi. il s'agissait de sépultures de femme, et mème, a-t-on pu le préciser pour l'Ilot-les-Vases et Bouillé-Courdault, de jeune femme, comme ici. Au cimeliere des Dunes a Poiliers - F. Eycun l'avait déjà noté - "les sépultures de femmes el d'enfants sont de beaucoup les plus riches "38. si done la cilé des l'ictones n'avait pas l'exclusivité d'un tel usage, on peul dire que celui-ci y était partirulierement a l'honneur. Mais la encore la sépulture de Niort-Bessines se place chronologiquement au meilleur rang. puisque les sépultures vendéennes qui viennent d'ètre évoquées s'échelonnent dans le temps de $120 / 130$ pour la première à fin $\mathrm{I}^{\mathrm{e}} / 11 \mathrm{e}^{\mathrm{e}}$ siecle pour la derniere ${ }^{39}$.

Remarquons que l'abondance de ces dépots funéraires semble bien correspondre a la persistance ou à la renaissance d'une Lradition gauloise, puisque au moins jusqu'à laa Téne II, époque où ils pratiquaient l'inhumation, les Gaulojs aimaient à emporter dans l'Au-delà leurs objets familiers qui étaient déposés en abondance dans leurs tombes, avec, romme ici, des "quartiers de pore le mels favori des Celtes" , ainsi que le rappelle dans un article de vulgarisation une eminente spécialiste ${ }^{40}$ A Boulle-dourdault, pour la sépulture ritér précérlemment, la tradition durait encore au Ine sierele, sous une forme semblable ḋ relle observé à Niort-Bessines, puisqu'on y a découvert une "demi-mârehoire " et des os de

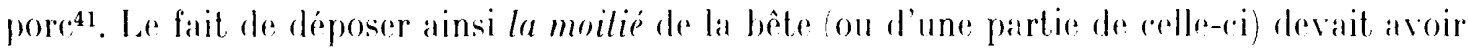
une valeur symbolique : ne peut-on penser qu'il marquait une intention de partage de cetle nourriture entre le défunt et ses proches survivants?

Mais une autre caractéristique des dépots mobiliers arcompagnant rette sépulture devait avoir aussi une signification particuliere. c'est le redoublement de bon nombre des objets qui les composaient :

denax amphores, den.r cruches (de tailles différentes. nos $1: 3$ et 14 pour s'en tenir à ce qui se trouvait a l'extérieur du sarcophage): puis dans le coffre pour la verrerie : dentrouleilles cylindriques (de tailles différentes), deux fois deus bouteilles carrées (dont deux issues du même moule), dentr urnes

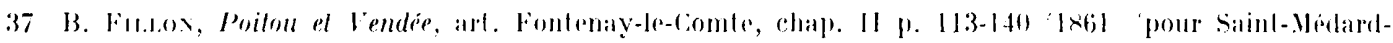

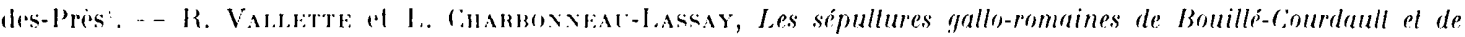

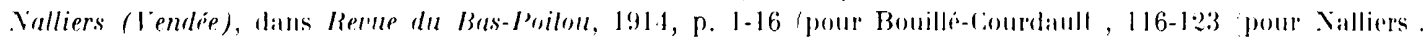

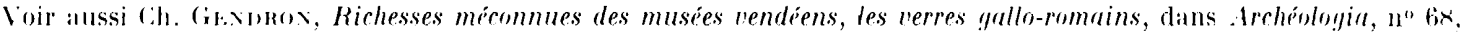
mats $1974,1,3(i-1)$.

$3 \times$ () sous lumulus ave abondant mohilier ast redativement frépuent entre l'epoque flavienne ot le deuxieme quart du

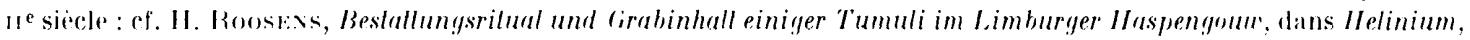

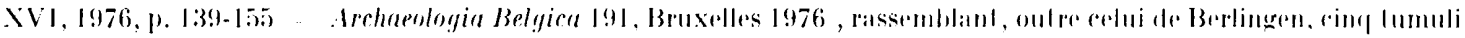
comportant des mobiliers sinon refuivaldonts du moins comparables.

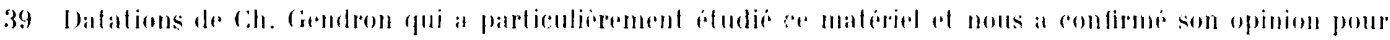

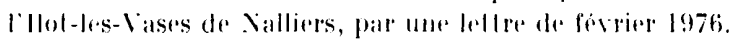

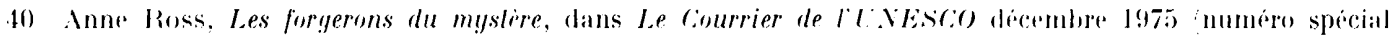

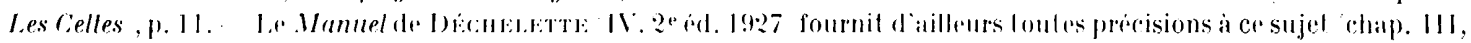
p. $51 \times+1 \mathrm{se}$.

$1101 \%$ cil., 11. 3. 1). 1\%. 
wö̈des mème type mème décor . deux fois deux plats cylindriques. deux fois deux bols, deux phiales en verre millefiori : deux balsamaires a panse piriforme $\left(\mathrm{n}^{\text {os }} 28\right.$ et 29 ), deux petits vases en forme de urappe de raisin : pour la céramique du coffre. deux plats et trois fois deux tasses Drag. 27 en céramique sigillée, et peut-ètre aussi deux grobelets en terre grise (nos 16 et 17). On pourra certes objecter que les autres piecces non reprises dans cette énumération sont en exemplaire unique. mais d'une part certaines pièces peuvent ètre restées inconnues par suite des prélivements clandestins (peut-être en particulier y avait-il une seconde patire. comme dans la sépulture de Berlingen); d'autre part si re redoublement avait un sens pour les auteurs de tels dépóts. il pouvait peut-ètre être réalisé à l'aide de pièces sinon de mème forme du moins de mème usage (par exemple pour la verrerie. les $n^{\text {os }} 7$ et 8 . les gobelets n ${ }^{\text {os }} 13$ et 1.4 de formes différentes ou au contraire souffrir certaines exceptions dans son application. Le fait nous a paru en tout cas se répéter trop de fois ici pour être simplement dì au hasard. On pourrait d'ailleurs donner d'autres exemples du mème fait. Ch. (iendron en cite à propos de la sépulture de Bouillé-Courdaull ${ }^{+2}$. Dans la sćpulture de Berlinợen ${ }^{43}$. la majorité des pieces de vaisselle se laissent regrouper par deux (mais aussi dans un cas a celui des cruches, par trois). Pour tenter une interprétation. il faudrait élargir l'enquête.

Yous aurions pu ajouter. a la liste d'objets en double qui précede. les deux monnaies recueillies dans le sarcophage. Cous avons hésilé a le faire. car. compte tenu de la statistique des dépòts monétaires que permet la publication du cimetière des Dunes à Poiliers. le fait nous paraît moins probant: Pln effet sur fifi tombes ayant livré des monnaies notées dans l'inventaire, 12 seulement en ont fourni 2. contre to une seule les autres 3. 6. ou 7). Le nombre ? ne correspond done qu'à l'un des deux cas principaux et pas le plus fréquent des dépòts monétaires funéraires.

Xous nous sommes efforcé de replacer la sépulture étudiée dans le contexte des rites funéraires pratiqués tant sur un plan général en Ciaule, que sur celui de la région à laquelle elle appartient. Yous n'avons pas cherché bien entendu à ètre exhaustif sur ce point, mais plutôt simplement à fournir un éclairage suffisant pour la compréhension de la découverte. La qualité du sarcophage en cause. à une époque où ce mode de sépulture commençait seulement à se répandre en Giaule. l'abondance et la variété du mobilier et l'importance des offrandes alimentaires qui l'accompagnaient, témoignent de l'appartenance de la défunte à une famille gauloise certainement aisée, conciliant sans doute un hon degré de romanisation avec le maintien de traditions ancestrales dans les rites funéraires.

A Siant-Médard-rles-Press. la riche sépulture que nous avons prise, avee d'autres. comme exemple de comparaison, a pu ètre rattachér à une villa assez luxueuse, découverte tout a còté au cours des mèmes travaux. Il serait intéressant sur le plan local de pouvoir en faire autant ici, gràce a des prospections heureuses. Ilais sur un plan plus général. lintérèt principal de cette sépulture. outre celui qu'elle présente pour les études relatives a la verrerie. demeure le jalon quidle constitue dans la connaissanere de l'apparition du sarcophlatere en Giatule romaine.

Pierre-Henri Mrrann.

4.) (1). cil., II. 37. p. 111.

13 (1). ril., 11. 15 .

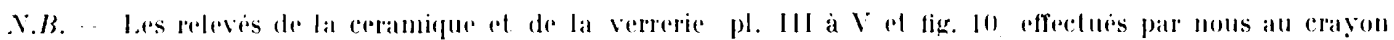
ont efe mis an nel par notre ami Ph. Simon. Qu'il nous soit permis de len remereier sincerement ici et dexprimer

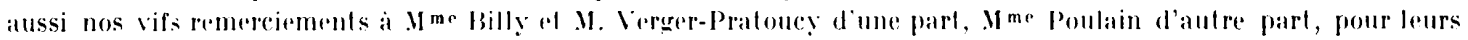
études particulieres figurant en anmexes. 


\section{ANive: 1

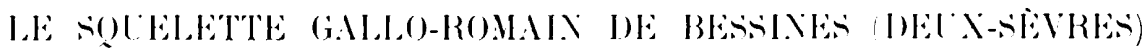 ETTLE ANTIROPOLOCIQLE}

Les restes squelettiques recueillis par M. P.-H. Mitard qui les altribue a la fin du I $^{\text {er }}$ siècle, constituent un matériel anthropologique d'autant plus précieux que l'incinération à rette époque prévalait partout en Gaule Romaine comme rite funéraire.

Ces restes humains comprennent une tète osseuse en asse\% bon état de conservation et un squelette post-rainien fort incomplet. ainsi que de tries petits fragments cràniens inutilisables appartenant à un enfant en bas àge. Les ossements adultes peuvent ìtre attribués sans aucun doute à une jeune femme d'une vinglaine d'années environ. Les sulures crâniennes ne présentent, en effel, qu'une très légère synostose au niveau de l'obélion tandis que les dents en place sont fort peu usées. En particulier. les troisiemes molaires ne sont pas en contact occlusal bien que la calcification de leur racine soit terminée, comme en témoignent les radiographies des régions molaires tant supérieure qu'inférieure.

Les os de l'enfant ne permettent pas, en revanche, une telle précision en ce qui concerne l'âge de la mort. Ce sont tous de trís petits fragments de la voùte crànienne dont les plus importants n'excedent pas 17 sur 22 mm et dont seule, leur extrème minceur laisse à penser que nous avons aflaire à un tris jeune enfant. ou peut-ître même à un fortus.

I. LA Tĥt: osistat:

Elle comprend un cràne incomplet, en l'absence de la region orbito-nasale correspondant aux maxillaires supérieurs el au malaire gauche ; la mandibule est en excellent étal de conservation.

Le crâne. Fialuée selon la formule de Pearson. la capacité crànienne est eunencéphale $\left.(120) 3 \mathrm{~cm}^{3}\right)$. l.e cràne est par ailleurs méso-brachycrâne (79.5).

Dimensions et indices du crâne

\section{Dimensions CRÂNE}

Longueur maximale $(1) \ldots \ldots \ldots \ldots \ldots, 171$

Longueur glabelle-inion (2) . . . . . . 162

Longueur basion-nasion (5) . . . . . . 89

Longueur du trou occipital $(7) \ldots \ldots \ldots \quad 36,5$

Largeur maximale (8) .......... 136

Largeur frontale min. $(9) \ldots \ldots \ldots \ldots .95$

Largeur frontale max. $(10) \ldots \ldots \ldots \ldots . .117$

Largeur du trou occipital $(16) \ldots \ldots \ldots . \quad 31$

Hauteur basio-bregmatique (17) ..... 123

Hauteur porio-bregmatique (20)..... 104
Indices

Indice crânien $(8 / 1) \ldots \ldots \ldots \ldots \ldots \ldots \quad 79,5$

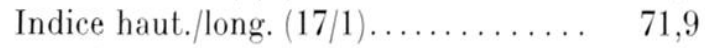

Indice haut./larg. $(17 / 8) \ldots \ldots \ldots \ldots \ldots 9.4$

Indice haut./long. $(20 / 1) \ldots \ldots \ldots \ldots \ldots \quad 60,8$

Indice haut./larg. $(20 / 8) \ldots \ldots \ldots \ldots \ldots \quad 76,5$

Indice fronto-pariétal $(9 / 8) \ldots \ldots \ldots \ldots \quad 69,8$

Indice frontal transv. $(9 / 10) \ldots \ldots \ldots \ldots \quad 81,2$

Indice frontal sagitt. $(29 / 26) \ldots \ldots \ldots \quad 86,6$

Indice pariétal sagitt. $(30 / 27) \ldots \ldots \ldots \quad 88,7$

Indice occipital sagitt. $(31 / 28) \ldots \ldots \ldots \quad 87,1$ 
Périmètre horizontal (23) . . . . . . . 495

Périmètre transversal (24) . . . . . . . . 298

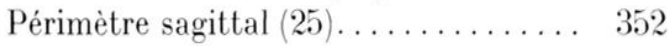

Arc frontal $(26) \ldots \ldots \ldots \ldots \ldots \ldots \ldots . . \ldots 119$

Are pariétal $(27) \ldots \ldots \ldots \ldots \ldots \ldots \ldots . \ldots \ldots$

Arc occipital (28) ............... 109

Corde frontale $(29) \ldots \ldots \ldots \ldots \ldots \ldots \ldots, 103$

Corde pariétale $(30) \ldots \ldots \ldots \ldots \ldots \ldots . \ldots$

Corde occipitale $(31) \ldots \ldots \ldots \ldots \ldots \ldots \quad 95$

FACE

Largeur bizygomatique (45). . . . . . . 126

Hauteur faciale totale (47) . . . . . . . 103

Hauteur faciale supérieure (48) ..... 63
Indice du trou occipital $(16 / 7) \ldots \ldots \ldots \quad 84,9$

Angle du prognathisme total $(72) \ldots . \quad 88^{\circ}$

Dimensions et indices mandibulaires

Longueur mandibulaire (68)........ 104

Largeur bicondylienne $(65) \ldots \ldots \ldots \ldots, 118$

Largeur bigoniaque $(66) \ldots \ldots \ldots \ldots \ldots, 103$

Hauteur symphyse $(69) \ldots \ldots \ldots \ldots .25$

Hauteur branche montante $(70) \ldots \ldots . \quad 57$

Largeur branche montante (71)..... 32

Hauteur du corps en $\mathrm{PM}_{2}-\mathrm{M}_{1} \ldots \ldots .24$

Hauteur du corps en $\mathrm{M}_{1}-\mathrm{M}_{2} \ldots \ldots \ldots \ldots 23$

Épaisseur réelle en $\mathrm{PM}_{2}-\mathrm{M}_{1} \ldots \ldots \ldots \ldots \quad 11,5$

Épaisseur réelle en $\mathrm{M}_{1}-\mathrm{M}_{2} \ldots \ldots \ldots \ldots \quad 12,5$

Épaisseur en projection en $\mathrm{PM}_{2}-\mathrm{M}_{1} \ldots \quad 20$

Épaisseur en projection en $\mathrm{M}_{1}-\mathrm{M}_{2} \ldots \ldots \quad 17$
Indice de long./larg. (68/65) . . . . . . . 88,1

Indice des largeurs $(66 / 65) \ldots \ldots \ldots \ldots \quad 87,3$

Indice branche montante $(71 / 70) \ldots \ldots \quad 56,1$

Indice de robustesse en $\mathrm{PM}_{2}-\mathrm{M}_{1} \ldots \ldots \quad 83,3$

Indice de robustesse en $\mathrm{M}_{1}-\mathrm{M}_{2} \ldots \ldots \ldots \quad 73,9$

Indice d'obliquité. . . . . . . . . 64,9

Angle goniaque.............. $119^{\circ}$

avec une voùte relativement basse en regard de sa longueur (orthocrane) comme de sa largeur (tapéinocrane). I.es indices moyens de hauteur au basion et au porion correspondent précisément. à un cràne bas.

En norma superior. le contour crinien est en forme d'ovoüde rourt. avec des bosses pariétales adoucies et une légrère plagriocéphalie droile (figr. 14). Ni les arcades \%yomatiques ni aurun segment facial ne sont visibles selon cette norma.

l.e front est large dans sa région de rétrécissement maximal comme au niveau de l'écaille; il est moyennement divergent. L'indice fronto-pariétal, aver une valeur de 69.8 est eurymétope. ce qui correspond a une forte dilatation du frontal minimum par rapport au diametre transverse.

Au niveau du pariétal. on note un faible développement des bosses et l'absence de trous pariétaux. Le renflement des parois latérales porte principalement sur l'écaille temporale qui tend ainsi à déborder le pariétal.

En norma laleralis, le front s'éleve droit et tres bombé. avec des bosses frontales bien marquée: au-dessus d'une glabelle dont la saille s'apparente a la ratégorie III de Marlin. Puis la courbe sagiltale décrit un segment franchement horizontal jusqu'au vertex silué environ au tiers du pariétal. Elle s'infléchil alors brutalement puis descend presque verticalement. L'orripital présente une nette planoceipilalie tandis que l'inion est a peine marque el l'apophyse mastoüde peu volumineuse.

Avec un périmetre sagittal de 3502 mm le ràne est court. la part respective de chacun des os de la voute se traduisant par la décroissance $P>F>0$. Enfin. malgré la détérioration du massif facial on peut aflimer que celui-ri est caractérisé par un orl hognalhisme parfait. 

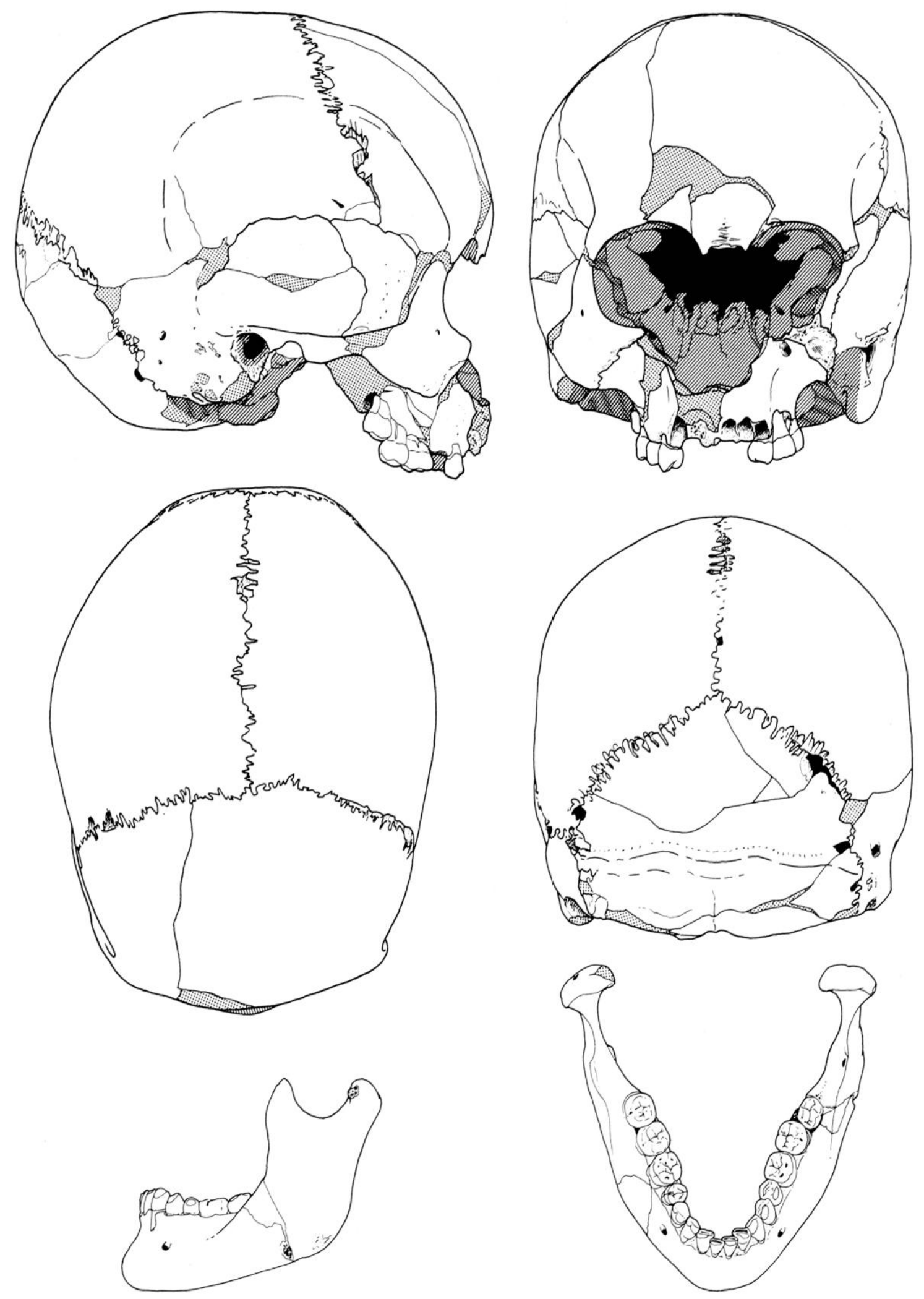

11 l.e conlour crànien. 
En norma poslerior. la voùte présente une forme pentagonoüde large et basse. Les. plans pariétaux sont par ailleurs sensiblement verticaux et le relief musculaire nuchal est peu marqué.

lin norma basilaris, le foramen magnum est mésosème (84.9) et elliptique. aver des lignes courbes orcipitales peu développées. I'ne arcade dentaire parabolique délimite une voùte palatine relativement profonde.

En norma facialis, notons un arrondi de la voùte et un renilement de l'écaille temporale remarquables. Le front est tris large tant en valeur absolue que par rapport a la largeur crànienne; il présente un rétrécissement sus-orbitaire prononcé arec des ares sourciliers à peine marqués.

La face basse et large est mesene (50).0) a tendance euryine. mais nettement euryprosope dans son ensemble. Toutefois le malaire est assez saillant. ce que confirme l'indice raniofacial dont la valeur 92.6 correspond a une branche cryptozygie.

La mandibule. son aspert est gracile aver un corps mandibulaire relit ivement bas et tris oblique. L'indice de longueur-largeur $(8 \times .1)$ se range dans la catégorie mésognathe. tandis que l'indice des largeurs (87.3) rorrespond ì une branche montante peu évasée.

La région antérieure ne présente pas de prognathisme alvéolaire. L.e menton est bien dessiné aver une saillie correspondant au schéma $n^{\circ}$ ( 6 de la classification de schult: (193:3). Le trou mentonnier. bien symétrique. est situé sous la $\mathrm{PVI}_{1}$ à égale distance des deux bords.

Les apophyses géni sur la face linguale sont presque inexistantes: on dénombre 4 surfaces d'insertion musculaire rugueuses mais sans aucun relief (type I-2 de J.-I. Heim, 196;3). Alors que la fosse sublinguale est a peine marquée. la ligne oblique interne en revanche est bien soulignée et surmonte une fosse sous-maxillaire fortement déprimée. L'architecture du bord inférieur correspond au schéma V1 de Schult \% pour lequel la mandibule repose sur la section postérieure rectiligne aver un gnathion très éloigné du point de contact.

La branche montante, moyennement laroge el élevée, parail élancée. L'empreinte massétérienne est à peine marquée et les gonions sont régulièrement arrondis (type I de schultz). Ju còté lingual, l'orifice du canal dentaire est limité en arant par une lingulae mandibulae moyenne, landis que le sillon mylo-hyoüdien en dessous, est bien défini. L'échancrure sigmoïde qui est creusée en demi-cercle répond au schéma I de schult\%. Notons aussi la forme triangulaire du coroné et un condyle cunéiforme avec un grand axe franchement perpendiculaire.

Enfin l'arcarde dentaire est de forme hyperbolique et les dents sont toutes en place.

Les dents. Il existe un cont raste frappant entre l'élat de la dent ure mandibulaire qui est excellent. et celui de la denture maxillaire pour laquelle les dents 11. 12. 13. 15 et 2.2, 223. 24, 28 sont absentes; étant donné l'aspert des alvéoles restants. on peut penser que toutes les dents manquantes ont disparu post-morlem.

L'inténrité de l'arcade inférieure permet d'assimiler la forme de celle-ci à une arcade dite en "lyre". le phénoméne étant d'ailleurs arcusé par la linguo-position du groupe prémolaire et molaire qui correspond a la disposition en "balconnet " de X. J. Dubecq (1962). En ce qui concerne la partie anlérieure. les légrires malpositions des incisives (rotations mésiales ou distales) ont entrainé un faible chevaurbement. Étant donné la forme de l'arrade précédemment décrite et l'absence d'espace rétro-molaire. il est permis de penser que re chevauchement s'est produil au moment de l'éruption des dents de sigesse.

Quant au maxillaire. une palalo-position prononede doit etre signalée pour la 2a) : par ailleurs. les conlacts proximaux des molaires et des prémolaires ne correspondent pas a la norme en égard. non seutement a la malposilion de la premolaire pour le ciote wauche. mais encore el surtout a la morphologie particuliere des deux premieres molaires qui es dicrile plus loin. Entin. les rapports d'orclusion permettent de penser que celle-ci at ait psalidodonte. 


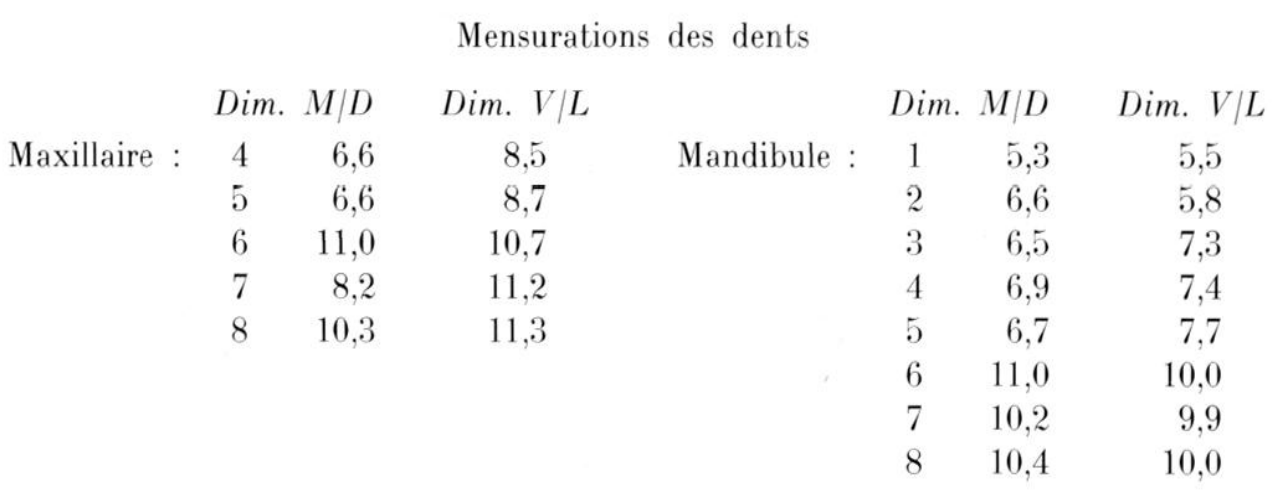

Les mensurations dentaires rapportées au tableau 111 ne prisentent aucune distorsion majeure avec celles de l'homme actuel. Il faut néanmoins noter une anisodontie pour les deuxiemes molaires supérieures et, surtout, l'importance volumétrique des dents de sagresse.

Aucune anomalie de forme n'est à signaler à la mandibule. Au niveau du maxillaire, en revanche. les deux premières molaires ( 16 et 17 en particulier) montrent un allongement vestibulo-palatin anormal. avec un diamètre mésio-distal de la 17 avoisinant $8.2 \mathrm{~mm}$. Il s'ensuit un hypocone relativement marqué. Le schéma des faces occlusales reste classique à la mandibule avec des formes Yó pour les 6 et Y4 pour les 7 . mais il est relativement perturbé dans le cas du maxillaire aver parfois Irois cuspides allongées dans le sens vestibulo-lingual en prolongement l'une de l'autre ; la disposition des sillons occlusaux des dents de sagesse paraît incliner vers la forme Y4.

L'usure, quoique peu prononcée (stade I à II pour les incisives el les premirres molaires), est assez caractéristique puisqu'elle intéresse essentiellemenl les versants vestibulaires des dents inférieures. Ine telle usure rend parfaitement compte de la position de ces dents el de l'articulé précédemment décrit (psalidodonte).

On n'observe par ailleurs aucune lésion dentaire due a la carie: mais au vu des traces de tartre encore adhérent à certains endroits, il y a tout lieu de penser que celui-ci était relativement abondant ; le déchaussement important constaté au maxillaire paraît dû néanmoins à des phénoménes postmortem, comme nous l'avons déjà souliơnó.

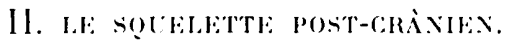

Clavicule. Seule subsiste la clavicule droite : bien qu'incomplète son aspect doit itre tenu pour uracile, aver des reliefs extrèmement adoucis. Le corps est très aplati sagitlalement comme l'altestent les valeurs des diamitres vertical $(1: 3 \mathrm{~mm})$ et sagittal $(9 \mathrm{~mm}$ / pris approximativement en son milieu.

Omoplate. (On dispose d'une omoplate gauche très incomplète. La cavité glénoïde (24,5) $\times 35 \mathrm{~mm}$ ) est pyriforme et l'épine. du type I de II. Vallois. possede un tubercule trapézien moyennement développé; l'acromion est quadrangulaire.

Humérus. Les extrémités supérieures manquent sur les deux humérus. Bien que daspect grarile. ils présentent une nette platyomie : le développement marqué du $\mathrm{V}$ deltö̈dien entraine en effet un aplatissement de la diaphyse el. par suite un élargissement de la fare antéro-externe de l'os. Löindice diaphysaire. évalué approximativement au milieu. indique un degré de platybrachie prononcé $(I-72)$. A l'extrémité supérieure. la gouttière bicipitale est ruqueuse mais i peine creusée. On note entin, la présence d'une perforation olécrânienne au niveau de l'épiphyse inférieure.

l'Ina. L'ulna droil subsiste seul. encore qu'incomplet en l'absence de son extrémité inférieure. La diaphyse est faiblement courbée mais la cròte interosseuse aiquä. Toutes les empreintes musculaires sont assez adoucies, le tubercule supinateur de mème que la rrète oblique étant peu déve- 
loppés. L'extrémité supérieure présente un faible degré de platolénie / $=79.5)$ el un sillon olérànororonö̈dien entier.

Radius. Radius qauche réduit a ses trois quarts inférieurs. I)'aspect gracile, la diaphyse est très fortement aplatie avec un indice de $71.4(10 / 14 \mathrm{~mm})$ et la crête interosseuse aiquë. Les empreintes musculaires sont peu marquées. La base de l'ext rémité inférieure, à peine roncave, ne présente aucune separation de la surface articulaire.

Bassin. Bien que tris incomplet, l'existence d'un fragment d'os coxal gauche a contour tris élargi de la grande échancrure sciatique permet de confirmer l'attribution de re squelelte au sexe féminin.

Fémur. Les deux os sont entiers. D'aspect élancé. avec des insertions musculaires peu prononcées et un pilastre faible, ils se situent à la limite platymérie-eurymérie comme le montrent les valeurs indicielles du tableau suivant.

\section{Mesures et indices des fémurs}

D. G. D. $\quad$ G

Longueur en position $(2) \ldots \ldots .452 \quad 454 \quad$ Diam. vert. tète $(18) \ldots \ldots \ldots .42 \quad 42$

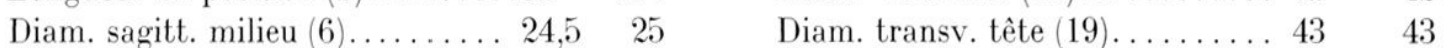

Diam. transv. milieu (7) . . . . . 26 $26 \quad$ Ind. de robustesse $(6+7 / 2) \ldots \ldots 11,2 \quad 11,2$

Périm. au milieu $(8) \ldots \ldots \ldots \ldots .79 \quad 80 \quad$ Ind. pilastrique $(6 / 7) \ldots \ldots \ldots \ldots 94,2 \quad 96,1$

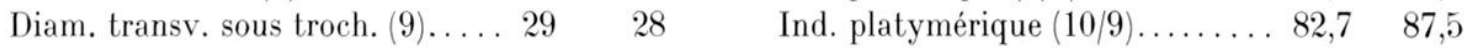

Diam. ant.-post. sous troch. (10). $24 \quad 24,5 \quad$ Ind. de la tête $(19 / 18) \ldots \ldots \ldots \ldots 102,4 \quad 102,4$

Ia tête fémorale, sensiblement sphérique, est relativement pelite. La crête fessière existe seule sans troisieme trochanter ni fosse hypotrochantérienne. Enfin, la courbure de l'os est plutót faible.

Tibia. Seul subsiste le tibia droit, moyennement robuste, qui posside des empreintes musculaires asse\% peu marquées el une lubérosité antérieure peu volumineuse. I'aplatissement de la diaphyse n'est pas très sensible et détermine un indice mésocnémique.

\section{Mesures et indices du tibia (droit)}

Longueur totale $(1) \ldots \ldots \ldots \ldots \ldots \ldots 366 \quad$ Ind. de robustesse $\left(10_{b} / 1\right) \ldots \ldots \ldots, 8$

Diam. ant.-post. au trou nour. ...... $32 \quad$ Ind. cnémique (D.T./D.A.P.) . . . . . 67,2

Diam. transv. au trou nour. ........ 21,5

Périm. minimal $(10 \mathrm{~b}) \ldots \ldots \ldots \ldots \ldots .69$

Fibula. Lios grauche est presque entier; on peut évaluer approximativement sa longueur maximale à 3:) $10 \mathrm{~mm}$. La région médiane de la fare antéro-externe est netlement cannelée.

Reconslilulion de la slalure. On dispose pour ce faire des longueurs des trois os longs du membre inférieur, pour lequel la corrélation aver la stature est la plus serrée.

L'emploi des Lables de Manouvier, conduit à une stalure moyenne de $161.4 \mathrm{~cm}$ qui se place dans la calégorie " hypsisome ". On remarquera l'identité des stalures déterminées à partir du fémur et du libia $(162,3 \mathrm{~cm})$.

$\begin{array}{llll}\text { Fémur }(d-g) & 453 \mathrm{~mm} & 162,4 \mathrm{~cm} \\ \text { Tibia }(\mathrm{d}) & 366 \mathrm{~mm} & 162.3 \mathrm{~cm} & \\ \text { Fibula }(\mathrm{g}) & 3500 \mathrm{~mm} & 159,6 \mathrm{~cm}\end{array}$

A titre de comparaison, nous avons aussi utilisé quelques régressions de Pearson basées uniquement sur les longueurs du fémur et du tibia. Elles conduisent aux résultats suivants : 


\begin{tabular}{|c|c|c|}
\hline Slalure $=1,945$ & Fémur $72 \times 1$ & $=1630,9 \mathrm{~cm}$ \\
\hline slature $=2.35$ & Tibia $: 7.7 .77$ & וי \\
\hline $1: 3$ & (Fémur ; Tibia) ; (ig,li) & $=161.7 \mathrm{r}$ \\
\hline Lature & Fimur $+1,125$ Tibia - & |ilis \\
\hline
\end{tabular}

Selon ces evaluations, la valeur moyenne $161.2 \mathrm{~cm}$ est extremement proche de celle obtenue selon Manouvrier. On peut donc en conclure à un sujet féminin de grande laille.

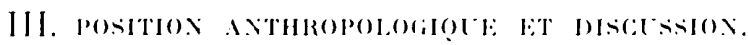

Ces restes asseux appartiennent à une jeune femme d'une vingtaine d'annés. de urande laille. presque brachycràne. La voùte crànenne. légèrement aplatie, présente une convexilé réguliere aver planocripilalie. Ie front est large et bombé. Le massif facial, orthognathe el ryptozye. est. a la fois large el bas. I a mandibule, modérément large, est mésognathe aver un menton triangulaire bien dessiné et fortement saillant. un corps mandibulaire tres oblique, une branche montante clancées et des gonions arrondis.

Ainsi décrit, ce cràne possede indéniablement rertains caractères propres aux Mppins classiques, comme la tendance marquée a la brachycranie. la voule hasse. le fronl droit el bombé. le renflemenl. de l'écaille temporale, de mime que la face basse el large aux orbit es moyennement haules.

Il y a lieu de rappeler aussi certains trats qui séartent de ceux allribues habituellement. aux Alpins. C'est la stature relalivement élevée. l'allongement du segment pariétal a courbure adoucie qui lui confère un contour ovoüde. le faible développement des bosses pariétales el l'étroitesse relative de la boîle crànienne.

On se trouve donc en présence d'un ensemble morphologique alpinoïde et il est lentant de considérer le sujet féminin de Bessines comme un jalon inlermédiaire dans le processus de brachyrânisalion qui s'est intensifié surtoul a partir du Moyen Âge (Billy, 1976) pour conduire aux formes eurysomes caractéristiques des Alpins (Billy. 1962). s'il en étail ainsi, il faudrait admeltre qu'un tel processus s'est développé trés tòt en Poitou.

Or, il est important de noter a cet endroit que le squelette de Bessines présente une morphologie rànenne identique à celle d'une femme mérovingienne trouvée à une vingraine de kilomitres plus au sud, a lsseau (Billy, 1967). La continuité dans le temps d'un même type morphologique qui se relrouve encore de nos jours chez les populations brachycéphales du Poitou est Loul a fait remarquahle. Elle implique que la brachycrànie s'est implantée de longue dale en Poitou et que le lype humain represente par la femme gallo-romaine de Bessines pourrait constituer le fond de population de celte région.

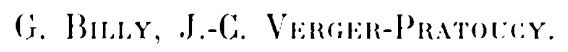

\section{BIBLIOGRAPHIE}

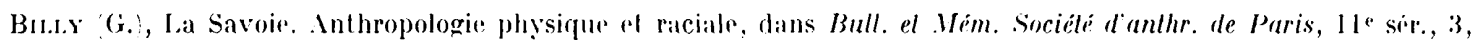
$1962,21 \times p$.

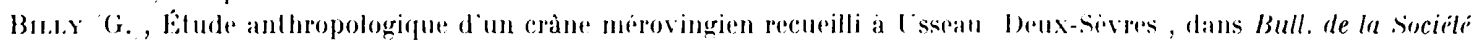
historique el scientifique des Denx-Sieres, 13, 1967, p. 27-285.

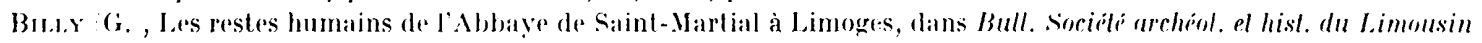
103,1976, p. 63-74.

Deвнся 'X. J.), Cours clinique de palhologie-stomalologique, Bordeaux 1962-1963.

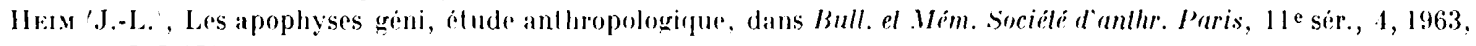
p. $585-658$.

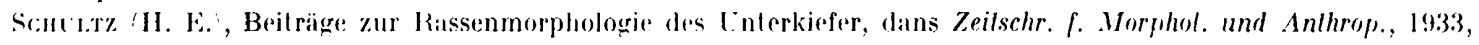
32, p. $236-275$.

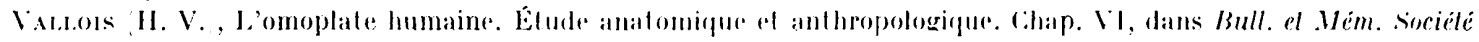
d'Anthr. Paris, x' sér., 3, 1932, p. 3-153. 
A.NEX: II

\section{ETLDE DES VESTIGE OSSELA I) ANIMALA}

Yous arons examiné 20:3 fragments osseux dont 17x déterminables, appartenant à un nombre minimum de 18 animaux pour la plupart domestiques. Les espèces sont peu variées :

animantr domesliques:

le boxul' (Bos laurus L.)

le porc: (Sus domesticus L.)

le mouton (Ovis aries L.)

te cheval (Equnus caballus L.)

te (hien (Canis familiaris L.)

le poulet (Gallus sp.)

animaux sauvages:

le lipvre (Lepus europaeus I'allas).

Ces fragments ont été trouvés en 4 points principaux : la fosse destinée à recevoir le sarcophage,

le sarcophage proprement, dit, les déblais trouvés à proximité. la partie située sous le sarcophage.

La fosse. Nous avons identifié 111 fragments osseux provenant de 3 porcs adultes, âgés d'environ 4 ans. L'un d'eux est un mâle; nous n'avons pu malheureusement reconnaitre avec certitude le sexe des deux autres. Les vestiges élaient groupés en plusieurs points : le long de la paroi ouest du sarcophage se trouvaient:

a) 1 maxillaire supérieur grauche (adulte màle).

3) fragments de :3 mandibules gauches, 1 branche montante de mandibule.

1 arriere-cràne aver son temporal, son occipital et sa bulle tympanale gauche.

1 deuxieme arrière-cràne avec le temporal et la bulle tympanale gauche.

le troisieme temporal el lat bulle tympanale gauche,

1 fragment d'arcade zygomatique gauche,

21 petits fragments cràniens,

15) fragments de còtes.

2 atlas, 1 fragment de verlibre cervicale.

l'extrémité distale d'l cubitus gauche. 2 os du carpe (scaphoindes gauches).

1 fragment proximal de fémur ;

b) 3 humérus, :3 cubitus, :3 radius grauches.

3 omoplates gauches.

c'est-à-dire les membres antérieurs des 3 pores.

Près de l'angle sud-ouest et au-delà ont été recueillis:

a) le membre postérieur gaurhe d'l des animaux:

le fémur, le tibia, le calcaneum. l'astragale, la rotule. l'os iliaque, 
b) des fragments des 2 autres membres postérieur's gauches. des coites el des vertibres:

2 fémurs grauches. I tibia. 1 rotule. 1 ralcaneum. 1 astragale.

2 os iliaques grauches,

30 fragments de còtes,

2 apophyses transverses de vertèbres lombaires,

1 fragment de sacrum.

Le sarcophage : 8 fragments d'l poulet adulte : 2 fragments d'humérus, 1 carpomélacarpien droit, 1 fragment de bréchel, 1 vertiebre cervicale. les vertibres lombaires. le salcum. l'omoplate gauche.

Les déblais: 79 fragments osseux dont 54 déterminables, appartenant à 10 animaux domestiques et sauvages :

bouf, porc, mouton, cheval. chien, poulet.

lièvre.

\begin{tabular}{|c|c|c|c|}
\hline Animaux & $\begin{array}{l}\text { Nombre de } \\
\text { fragments }\end{array}$ & $\begin{array}{c}\text { Nombre d' } \\
\text { individus }\end{array}$ & $\%$ d'individus \\
\hline bœuf....... & 2 & 1 & $10 \%$ \\
\hline porc......... & 27 & 2 & $20 \%$ \\
\hline mouton...... & 5 & 1 & $10 \%$ \\
\hline cheval........ & 1 & 1 & $10 \%$ \\
\hline chien......... & 1 & 1 & $10 \%$ \\
\hline poulet. . & 15 & 3 & $30 \%$ \\
\hline lièvre........ & 3 & 1 & $10 \%$ \\
\hline
\end{tabular}

Les animaux domestiques représentent $90 \%$ de la faune. Parmi eux le poulet est prédominant avec 3 individus. Le porc arrive en deuxième position aver 2 animax.

Âge: un seul jeune : 1 porc de 2 ans environ.

Répartition des resliges.

Le bruf : 2 fragments : 1 phalange I postérieure. 1 phalangre I antéricure.

Le porc: 27 fragments d'1 jeune de 18 mois-2 ans et 1 adulte :

le fémur droit, le fémur gauche, la rotule droite, le métatarsien gauche III, 1 phalange I postérieure (jeune),

1 fragment de l'humérus droit, le cubitus gauche, les 4 métacarpiens gauche, 1 phalange 1 antérieure (jeune),

1 os iliaque droit (ad).

3 vertèbres dorsales (ad),

6 fragments de còtes (ad),

l'arrière-cràne, l'os malaire, 1 fragment du maxillaire sup. qauche (i),

la rangée dentaire supérieure gauche (j),

2 fragments d'une M2 inférieure (ad).

Le moulon : 5 fragments d'l jeune adulte :

1 fragment de la diaphyse d'un métatarsien,

1 fragment de diaphyse radiale gauche,

2 fragments de còtes,

1 mandibule gauche. 
Le cheval : la poulie distale d'un métatarsien droit (ad) scié.

Le chien : l'intermaxillaire supérieur gauche d'un gros adulte.

Le poulet : 15 fragments de 3 poulets : 1 adulte jeune et 2 adultes plus âgés.

2 fémurs droil, 1 lémur wauche $; 1$ tibia droil, 1 tibia gauche $; 2$ phalanges post.

2 humérus droit, 1 gauche (plus petit), 1 fragment de diaphyse humérale ; l'extrémité distale d'l radius droit,

1 omoplate droite; 1 fragment d'os iliaque; 1 coracoïde droit; 1 còte.

Le lièvre : 3 fragments d'1 adulte :

1 diaphyse tibiale, -1 humérus gauche, 1 fragment de radius gauche.

Sous le sarcophage: 5) fragments de 4 animaux adultes : bouf, porc, mouton, poulet.

Le breuf' : un fragrment de molaire supérieure.

Le porc : l'extrémité distale d'une phalange I antérieure.

Le moulon : un fragment de diaphyse tibiale gauche.

Le poulet : un fragment d'os iliaque et 1 fragment de còte.

Thérèse Poulain. 